\title{
A CONTRIBUTION TO KNOWLEDGE OF THE GENUS CONIOPTERYX (NEUROPTERA: CONIOPTERYGIDAE) IN MADAGASCAR, WITH DESCRIPTIONS OF 18 NEW SPECIES
}

\author{
GYÖRGY SZIRÁKI \\ Department of Zoology, Hungarian Natural History Museum \\ H-1088 Budapest, Baross utca 13, Hungary \\ E-mail: sziraki.gyorgy@nhmus.hu,https://orcid.org/0000-0002-9052-9711
}

\begin{abstract}
Descriptions of 18 new species of Coniopteryx (Neuroptera: Coniopterygidae) from Madagascar are given, while Coniopteryx (X.) botswana Meinander, 1998 is reported as new to the fauna of this country. The new species are: Coniopteryx (C.) ambalihana sp. n., Coniopteryx (C.) auricularia sp. n., Coniopteryx (C.) bidentata sp. n., Coniopteryx (C.) corniculata sp. n., Coniopteryx (C.) crenata sp. n., Coniopteryx (C.) fianarantsoana sp. n., Coniopteryx (C.) geniculata sp. n., Coniopteryx (C.) harinhalai sp. n., Coniopteryx (C.) ihorombeana sp. n., Coniopteryx (C.) microcauda sp. n., Coniopteryx (C.) pseudoceylonica sp. n., Coniopteryx (C.) pseudomalgasensis sp. n., Coniopteryx (C.) ranomafanana sp. n., Coniopteryx (C.) schizostylaris sp. n., Coniopteryx (C.) spinicauda sp. n., Coniopteryx (C.) toamasinana sp. n., Coniopteryx (X.) antankarana sp. n., Coniopteryx (X.) tuleariensis sp. n. Also, Coniopteryx (X.) sestertia Meinander, 1998 is revalidated. The majority of the new species belong to the Coniopteryx lobifrons group; the distributional pattern of this species group is discussed.
\end{abstract}

Key words: Neuroptera, Coniopterygidae, distributional pattern, Madagascar, new species, revalidation.

\section{INTRODUCTION}

Earlier our knowledge about the coniopterygid fauna of Madagascar has been very poor. Before 1974 only a single Semidalis species was known from this large island as a representative of this family (FrASER 1952). A second species, Coniopteryx madagascariensis, was described by Meinander (1974). Later on, the same author reported further Coniopteryx specimens from there, but he regarded those as variations of his previously described species (MeINANDER 1998). In the framework of the Madagascar Project of the California Academy of Sciences (CAS) - among others - an extraordinarily large number of coniopterygids was collected. In the course of the studying of this material, it turned out that the above-mentioned specimens, which were regarded by Meinander (1998) as C. madagascariensis "variations”, actually represented three undescribed species (SzIRÁKi 2015). As a result of the further working up of the Madagascar dusty lacewing material, a considerable number of subsequent undescribed species came to light. For the correct judgment of the taxonomic position of several specimens, the investigation of the holotype of 
Coniopteryx (X.) botswana Meinander, 1998, and studying received information on the type specimens of Coniopteryx (X.) sestertia Meinander, 1998 were necessary.

\section{MATERIAL AND METHODS}

Apart from the holotype of Coniopteryx botswana Meinander, 1998, which was borrowed from the Insect Collection of the CAS (San Francisco), the examined material was collected in different parts of Madagascar in the framework of the Madagascar Project of the CAS. The vast majority of the coniopterygid specimens were captured by Malaise traps. The names of collectors are given in the following abbreviations: $\mathrm{ES}=$ Evert I. Schlinger, $\mathrm{F}=$ Brian Fischer, FP = Frank Parker, G = Charles E. Griswold, HH = Rasolondalao Harin'Hala, $\mathrm{I}=$ Michael Irwin, JR = Jean S. Randrianarisoa, JS = Jere Schweikert, $\mathrm{K}=$ David H. Kavanaugh, $\mathrm{MR}=$ Marie J. Raherilalao, $\mathrm{P}=$ Norman $\mathrm{D}$. Penny, $\mathrm{U}=$ Darell Ubick. As the locality data regards, an older province name "Diego Suares" was written on the original labels in several cases. It was corrected to "Antsiranana” in the present paper. Andasibe-Mantadia National Park is mentioned shortly as "Andasibe National Park" on the labels, and it also remained in this form below. On the other hand, this national park was mentioned in Antananarivo Province on some labels, though it is located in Toamasina Province. This mistake was corrected in the text. For the sake of the stability, in the descriptions of male genital sclerites I follow the essentially "neutral” terminology of Meinander (1972), though, a greatly promising recent attempt towards a homologization of these sclerites (AspöcK 2019 ) is available. The species are treated in alphabetical order within the subgenera, independently of their position of the (informal) species groups. Holotypes and most paratypes are deposited in the collection of CAS, while one or several paratype specimens of the new species are housed in Hungarian Natural History Museum (HNHM).

\section{TAXONOMY}

\section{Coniopteryx (Coniopteryx) ambalihana sp. n.}

(Figs 1-6)

Examined material - Holotype: male, Madagascar, Antsiranana Province, Ampasidava, Forêt d'Ambilanivy, $3.9 \mathrm{~km}$ S of Ambaliha, 13 $47^{\circ} 55^{\prime \prime} \mathrm{S}, 48^{\circ} 09^{\prime} 42^{\prime \prime} \mathrm{E}, 600 \mathrm{~m}$ a.s.l., 4-9. III. 2001, rain forest, Malaise trap, leg.: F, G et al.; deposited in the collection of CAS; CASTYPE number: 20010. Paratypes: 6 males, same data as holotype; 1 male, Madagascar, Antsiranana Province, 7 km N of Joffreville, $12^{\circ} 20^{\prime}$ S, $49^{\circ} 15^{\prime}$ E, 360 m a.s.l., 13-16. V. 2001, dry forest, Malaise trap, leg.: HH, 1 male, Madagascar, Fianarantsoa Province, Ranomafana National Park, radio tower at forest edge, $2^{\circ} 15^{\prime} 03^{\prime \prime}$ S, $47^{\circ} 24^{\prime} 26^{\prime \prime}$ E, $1130 \mathrm{~m}$ a.s.l., 15-22. XI. 2001, mixed tropical forest, Malaise trap, leg.: HH; 1 male, Madagascar, Toamasina Province, botanic garden near to entrance to Andasibe National Park, $18^{\circ} 55^{\prime} 35^{\prime \prime}$ S, $48^{\circ} 24^{\prime} 28^{\prime \prime}$ E, 1025 m a.s.1., 1-5. IX. 2001, tropical forest, Malaise trap, leg.: HH. Seven paratype specimens are deposited in the collection of CAS, while two are housed in HNHM.

Description: Length of the body 1.3-1.8 mm. Vertex, antennae and palpi light brown or pale ochreous, genae distinctly darker than vertex. Anterior edge of vertex with a prominent, laterally flattened projection. Eyes moderately large, black. Antennae 0.7-1.0 mm, 
25-29 segmented. Scape about as long as wide, pedicel 1.4 times longer than wide. Median flagellar segments cca 1.5-2.0 times wider than long, while proximal ones (apart from the last segment) about as long as wide. Pedicel and the first flagellar segment with a moderately large, setose outgrowth (Fig. 1). Some of the other basal flagellar segments have also small outgrowth with setae. Ordinary hairs are arranged in two regular rings on pedicel, and in two irregular ones on flagellar segments. Scale-like hairs cover the proximal half of pedicel loosely, and situated in an apical whorl on flagellar segments.

Legs and the large part of thorax light brown or pale ochreous; sutures, apodemes and the shoulder spots medium brown. Length of the fore wing 1.6-2.0 mm, of hind wing 1.2-1.6 mm. Wing membrane almost hyaline, or distinctly light brown. Pregenital part of abdomen pale ochreous.

Male terminalia (Figs 2-6) well sclerotized, medium or dark brown. Hypandrium about 1.3 times longer than high in lateral view. Processus terminalis very strong, and curved up sharply. Its median incision practically invisible in ventral view, while u-shaped in caudal view. Processus lateralis rather slender, and directed dorsally. Anterior apodeme of hypandrium laterally rather wide having a proximal lobe, medially narrow and curved backwards extremely. Gonarcus moderately sclerotized, without significant caudal projection and with narrow ventral apodeme. Stylus forked; its long outer branch curved forwards distinctly. Inner branch of stylus long and narrow, and there is an arched bridge

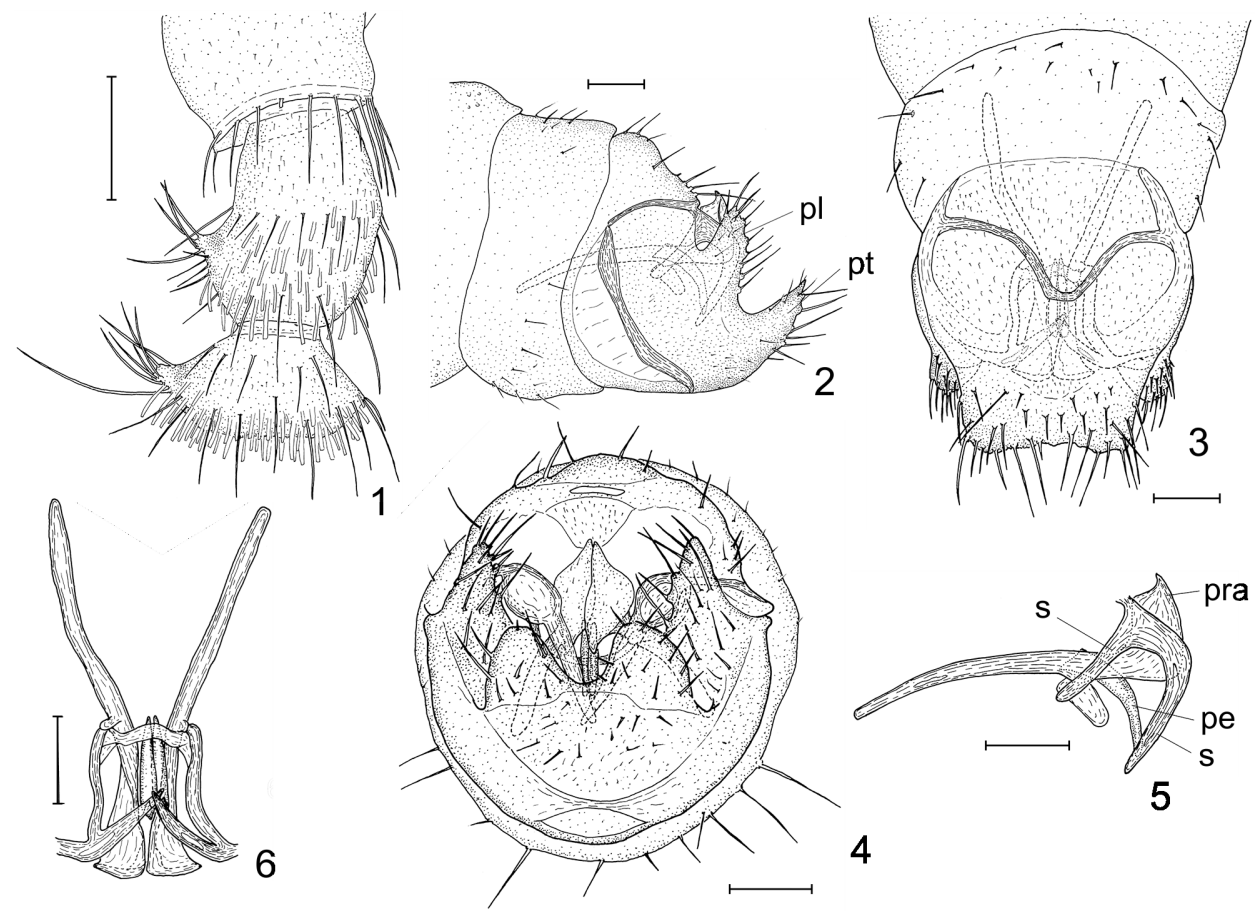

Figs 1-6. Coniopteryx (C.) ambalihana sp. n.: 1 = basal part of antenna, 2 = male terminalia, lateral view, $3=$ male terminalia, ventral view, $4=$ male terminalia, caudal view, $5=$ male internal genitalia, lateral view, $6=$ male internal genitalia, ventral view. Abbreviations: pe = penis, $\mathrm{pl}=$ processus lateralis of hypandrium, $\mathrm{pra}=$ processus apicalis of paramere, $\mathrm{pt}=$ processus terminalis of hypandrium, $\mathrm{s}=$ stylus. Scales: $0.04 \mathrm{~mm}$. 
between the two inner branches. Paramere evenly bent in lateral view. Processus ventralis of this sclerite small. Processus apicalis moderately large, and directed upwards. Its ventro-caudal angle in lateral view rounded, in caudal view sharp. The penis sclerite consists of two distinctly sclerotized rods truncated at their anterior ends.

Remarks: Coniopteryx (C.) ambalihana sp. n. belongs to the Coniopteryx lobifrons group sensu SzIRÁKi 2005, and is close to Coniopteryx (C.) malgasensis Sziráki, 2015.

The main distinctive features of the new species are:

- $\quad$ hypandrium distinctly longer than high in lateral view;

- $\quad$ processus terminalis of hypandrium very strong, and curved up sharply;

- $\quad$ processus lateralis rather slender and directed dorsally;

- median part of the anterior apodeme of hypandrium curved backwards extremely;

- $\quad$ inner branch of stylus narrow and long.

Etymology: The new species is named after Ambaliha, as most of the type material was collected at a locality situated near this town.

\section{Coniopteryx (Coniopteryx) auricularia sp.n.}

(Figs 7-12)

Examined matreial - Holotype: male, Madagascar, Antananarivo Province, 3km NE of Andranomay, $11.5 \mathrm{~km}$ SSE of Anjororobe, 18 $28^{\prime} 24^{\prime \prime}$ S, 47 $57^{\prime} 36^{\prime \prime}$ E, $1300 \mathrm{~m}$ a.s.l., mountain rainforest, 5-13. XII. 2000, Malaise trap, leg.: F, G et al.; deposited in collection of CAS; CASTYPE number: 20011. Paratype: 1 male, same data as holotype; deposited in HNHM.

Description: Length of the body $1.2-1.6 \mathrm{~mm}$. Coloration of the investigated specimens surely has been lost because of the insufficient preservation; the whole body, antennae, palpi and legs pale ochreous. Anterior edge of vertex with a prominent, laterally flattened projection. Eyes rather small, black. Antennae (Fig. 7) $1.1 \mathrm{~mm}, 29$ segmented. Scape as long as wide, pedicel slightly longer than wide. Flagellar segments (without the outgrowth of the first one) about 1.7 times wider than long. Pedicel without any outgrowth, but has a group of several stout setae. First flagellar segment has a bulky outgrowth, with rather short setae. The long ordinary hairs are arranged sparsely on scape and in two rather irregular rings in apical half of pedicel and flagellar segments. Scale-like hairs long, situated on considerable part of pedicel and in a broad apical whorl on flagellar segments.

Legs and thorax pale ochreous, thoracal sutures and apodemes and the shoulder spots light brown. Length of the fore wing 1.8-2.0 mm, of hind wing 1.2-1.3 $\mathrm{mm}$. Wing membrane hyaline. Pregenital part of abdomen pale ochreous.

Male terminalia as Figs 8-12. Hypandrium 1.5 times higher than long in lateral view. Processus terminalis rather narrow, with a rounded caudal ending and without median incision. A well sclerotized inner structure is connected to the dorsal surface of hypandrium. This structure consists of a sharp crest and a medially narrow anterior part, with 
two large prominent, ear-shaped lobes. The dorso-caudally directed processus lateralis rather large, with moderately long setae. Anterior apodeme of hypandrium evenly narrow. Besides, a membraneous structure is visible between the processes laterales and processus terminalis. Gonarcus moderately sclerotized, with thin ventral apodeme. Stylus forked; its outer branch long, and curved almost entirely forwards. Inner branch of stylus is a simple, moderately broad belt. No ventral bridge between the two inner branches. Paramere rather long, slightly bent, tapering anteriorly in lateral view, straight and slightly clubbed in ventral view. Processus apicalis moderately large, with an ending curved upwards, pointed in lateral view, and it has a dorsal broadening subapically. Processus ventralis of paramere seems to be absent. Penis sclerite consists of two moderately long, acute and slightly bent rods. Caudally and laterally of penis there is a slightly chitinized, in ventral view elongated, u-shaped additional sclerite.

Remarks: Coniopteryx (C.) auricularia sp. n. belongs to the Coniopteryx lobifrons group sensu SzIRÁki (2005). Because of the narrow processus terminalis, the shape of the processus lateralis, presence of an additional sclerrite around the penis and the long outer branch of the stylus it is close to Coniopteryx $(C$. angusticauda Sziráki, 2015.
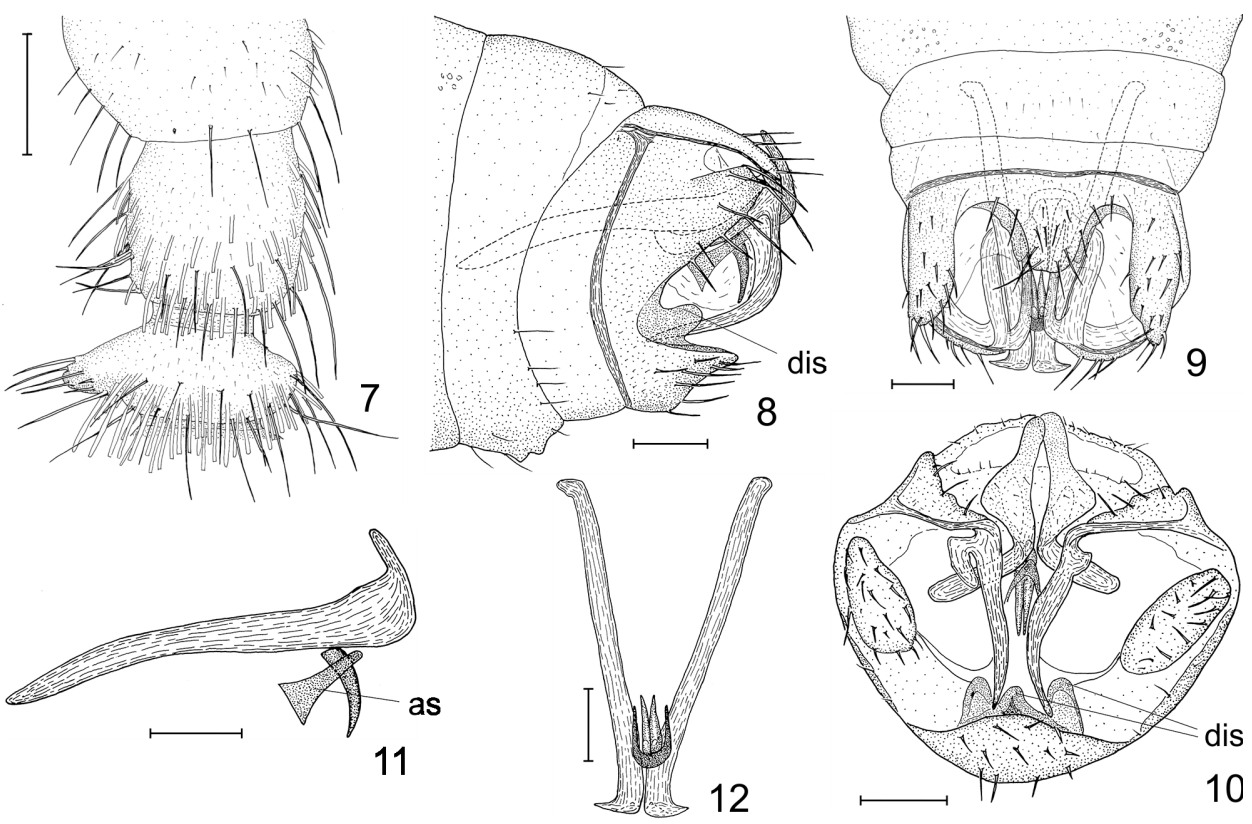

Figs 7-12. Conioptetryx (C.) auricularia sp. n.: $7=$ basal part of antenna, $8=$ male terminalia, lateral view, $9=$ male terminalia, ventral view, $10=$ male terminalia, caudal view, $11=$ paramere, penis and additional sclerite, lateral view, 12 = paramere, penis and additional sclerite, ventral view. Abbreviations: as $=$ additional sclerite, dis $=$ dorsal inner structure of hypandrum. Scales: $0.04 \mathrm{~mm}$ 
The main distinctive features of the new species are:

- the broad apical whorl of the scale-like hairs on the flagellar segments of antennae;

- $\quad$ the bulky setose outgrowth on the first flagellar segment;

- processus terminalis of hypandrium rounded caudally, without median incision;

- processus ventralis of paramere absent or indistinct;

- posterior part of the inner structure connected to the dorsal surface of the hypandrium is a single crest, while the anterior part of this structure has two large, prominent lateral lobes.

It is worth to mention that C. (C.) auricularia allied also to C. (C.) spinicau$d a$ (its description see below in present paper), but the rounded ending of the processus terminalis, the prominent lateral lobes of the inner structure connected to the dorsal surface of hypandrium, the absence of a distinct subapical lobe in the processus apicalis of paramere and the presence of the additional sclerite around the penis clearly separate the two species.

Etymology: The new species is named after the ear-shaped lateral lobes of the inner structure connected to the dorsal surface of the hypandrium.

\section{Coniopteryx (Coniopteryx) bidentata sp. $\mathrm{n}$.}

(Figs 13-17)

Examined material - Holotype: male, Madagascar, Tulear Province, Berenty Special

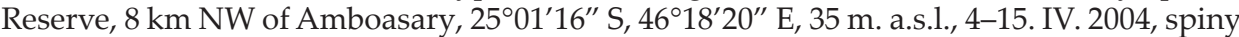
forest, Malaise trap, leg.: I, FP \& HH; deposited in the collection of CAS; CASTYPE number: 20012. Paratypes: 1 male, Madagascar, Antsiranana Province, Forêt de Binara, $7.5 \mathrm{~km}$ SW of Daraina, $13^{\circ} 15^{\prime} 18^{\prime \prime}$ S, $49^{\circ} 37^{\prime} 00^{\prime \prime}$ E, $375 \mathrm{~m}$ a.s.l., 1. XII. 2003, tropical dry forest, Malaise trap, leg.: F; 1 male, Madagascar, Antsiranana Province, $7 \mathrm{~km} \mathrm{~N}$ of Joffreville, $12^{\circ} 20^{\prime} \mathrm{S}$, 49 ${ }^{\circ} 5^{\prime}$ E, 360 m a.s.1., 20. III - 7. IV. 2001, dry forest, Malaise trap, leg.: HH; 1 male, Madagascar, Antsiranana Province, Montagne d'Ambre National Park, 12³0'52" S, 49 $10^{\prime} 53^{\prime \prime}$ E, 960 m a.s.l., 26-29. I. 2001, Malaise trap, leg.: I, ES \& HH; 1 male, same data but 19. III - 5. IV. 2001; 1 male, Madagascar, Antsiranana Province, Montagne d'Ambre National Park, 12 $31^{\prime} 13^{\prime \prime}$ S, $49^{\circ} 10^{\prime} 45^{\prime \prime}$ E, 1125 m a.s.l., 29. I - 11. II. 2001, Malaise trap, leg.: HH; 2 males, same data but 5-21. IV. 2001; 1 male, Madagascar, Antsiranana Province, Montagne des Français, $12^{\circ} 18^{\prime} 08^{\prime \prime}$ S, $49^{\circ} 38^{\prime} 51^{\prime \prime}$ E, $150 \mathrm{~m}$ a.s.l., 15. II - 6. III. 2001, along a forested limestone ridge, Malaise trap, leg.: HH; 1 male, same data but 6-20. III. 2001; 1 male, Madagascar, Antsiranana Province, Sakalava Beach, $12^{\circ} 15^{\prime} 46^{\prime \prime}$ S, $49^{\circ} 23^{\prime} 51^{\prime \prime}$ E, $10 \mathrm{~m}$ a.s.l., 28. VIII - 12. IX. 2001, dwarf littoral forest, Malaise trap, leg.: HH; 1 male, Madagascar, Fianarantsoa Province, near to Isalo National Park, at a stream E of Interpretive Center, $22^{\circ} 37^{\prime} 36^{\prime \prime}$ S, $45^{\circ} 21^{\prime} 29^{\prime \prime}$ E, 750 m a.s.1., 21-29. XII. 2001, open area, Malaise trap, leg.: HH; 1 male, same data but 30. III - 7. IV. 2002; 1 male, Madagascar, Fianarantsoa Province, near to Isalo National Park, 
E of Interpretive Center, $22^{\circ} 37^{\prime} 36^{\prime \prime}$ S, $45^{\circ} 21^{\prime} 29^{\prime \prime}$ E, $885 \mathrm{~m}$ a.s.1., 13-20. V. 2002, dry stream bed, Malaise trap, leg.: HH; 1 male, same data but 27. V - 4. VI. 2002; 1 male, same data but 22-30. VI. 2002; 1 male, same data but 3-10. X. 2002; 1 male, same data but 9-23. VIII. 2003; 1 male, Madagascar, Fianarantsoa Province, Ranomafana National Park, Belle Vue at Talatakely, $21^{\circ} 15^{\prime} 59^{\prime \prime}$ S, $47^{\circ} 25^{\prime} 13^{\prime \prime}$ E, $1200 \mathrm{~m}$ a.s.l., 19-26. II. 2002, secondary tropical forest, Malaise trap, leg.: HH; 2 males, Madagascar, Mahajanga Province, Ampijoroa National Park, $160 \mathrm{~km} \mathrm{~N}$ of Maevatana on RN 04, 16 ${ }^{\circ} 19^{\prime} 10^{\prime \prime}$ S, $46^{\circ} 48^{\prime} 48^{\prime \prime}$ E, 43 m a.s.l., 24-31. VIII. 2003, deciduous forest, Malaise trap, leg.: HH, 1 male, same data but 7-14. IX. 2003; 1 male, same data but 14-22. IX. 2003; 2 males, same data but 22-28. IX. 2003; 2 males, Madagascar, Mahajanga Province, Baie de Bali National Park, $124 \mathrm{~km}$ NNW of Soala, $16^{\circ} 00^{\prime} 36^{\prime \prime}$ S, 45 $15^{\prime} 54^{\prime \prime}$ E, $10 \mathrm{~m}$ a.s.l., 26-30. XI. 2002, tropical dry forest, Malaise trap, leg.: F, G et al.; 2 males, Madagascar, Mahajanga Province, Mahovavy River, $6.2 \mathrm{~km}$ SE of Mitsinjo, $16^{\circ} 03^{\prime} 06^{\prime \prime} \mathrm{S}, 45^{\circ} 54^{\prime} 30^{\prime \prime} \mathrm{E}, 20 \mathrm{~m}$ a.s.l., 1-5. XII. 2002, gallery forest, at light, leg.: F, G et al.; 1 male, Madagascar, Mahajanga Province, Tsingy de Bemaraha National Park, $10.6 \mathrm{~km}$

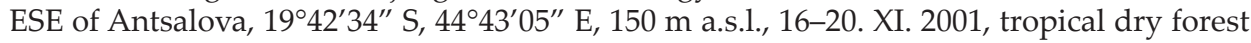
on tsingy, Malaise trap, leg.: F, G et al; 1 male, Madagascar, Tulear Province, Andohahela National Park, Forêt d'Ambohibory, $1.7 \mathrm{~km}$ ENE of Tsimelahy, $36.1 \mathrm{~km}$ NW of Talagnaro, $24^{\circ} 55^{\prime} 48^{\prime \prime}$ S, $46^{\circ} 38^{\prime} 44^{\prime \prime}$ E, 300 m a.s.l., 16-20. I. 2002, tropical dry forest, Malaise trap, leg.: F, $\mathrm{G}$ et al.; 2 males, Madagascar, Tulear Province, Berenty Special Reserve, 8 km NW of Amboasary, $2^{\circ} 00^{\prime} 24^{\prime \prime}$ S, $46^{\circ} 18^{\prime} 12^{\prime \prime}$ E, $85 \mathrm{~m}$ a.s.l., 23-30. XI. 2002, gallery forest, Malaise trap, leg.: I, FP \& HH; 1 male, same data but 26. I. - 5. II. 2003; 1 male, Madagascar, Tulear Province, Cap Sainte Marie Special Reserve, $12.3 \mathrm{~km} \mathrm{~W}$ of Morowato, $25^{\circ} 34^{\prime} 54^{\prime \prime} \mathrm{S}, 45^{\circ} 16^{\prime} 06^{\prime \prime}$ E, $200 \mathrm{~m}$ a.s.l., 11-15. II. 2002, spiny forest, Malaise trap, leg.: F, G. et al.; 1 male, Madagascar, Tulear Province, Ifaty, near Hotel Paradisia in costal dunes, $23^{\circ} 10^{\prime} 47^{\prime \prime}$ S, 43 $37^{\prime} 01^{\prime \prime}$ E, 9 m a.s.l., 26.V - 5. VI. 2002, vegetation in sandy area, leg.: HH; 2 males, Madagascar, Tulear Province, Mikea Forest, NW of Manambo, 22 $54^{\prime} 13^{\prime \prime}$ S, 43 $28^{\prime} 32^{\prime \prime}$ E, 30 m a.s.l., 6-16. XII. 2001, dry deciduous forest, Malaise trap, leg.: HH; 1 male, Madagascar, Tulear Province,

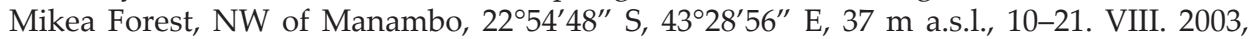
spiny forest, Malaise trap, leg.: HH; 1 male, Madagascar, Tulear Province, 16 km E of Saka-

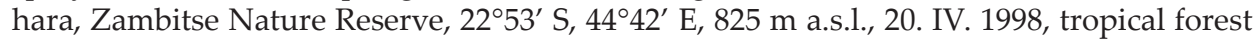
on sand, Malaise trap, leg.: I \& ES; 1 male, Madagascar, Tulear Province, Zambitse National Park, 22 $50^{\prime} 25^{\prime \prime}$ S, $44^{\circ} 43^{\prime} 52^{\prime \prime}$ E, 825 m a.s.l., 19-27. V. 2002, deciduous spiny forest, Malaise trap, leg.: HH. Majority of the paratypes are deposited in the collection of CAS, while 4 paratype specimens are housed in HNHM.

Description - Length of the body 1.1-1.6 mm. Head capsule and palpi without modifications, their colour light brown, but frons and vertex pale ochreous. Eyes moderately large, black. Antennae 0.7-1.0 mm, 23-27 segmented. Scape somewhat wider than long, pedicel slightly longer than wide, basal flagellar segments 2 times, median ones 1.6 times as wide as long. Antennal segments without projections. Ordinary hairs of flagellar segments situated rather irregularly. Setae moderately long. Scale-like hairs on the whole surface of the pedicel, in a dense whorl on the apical part of the majority of the flagellar segments, but irregularly on the $4-5$ apical segments.

Thorax pale ochreous with very dark sutures, apodemes and shoulder spots. Length of the fore wing 1.2-1.7 $\mathrm{mm}$, of hind wing1.0-1.4 $\mathrm{mm}$. Legs, wing membrane and veins brown. Pregenital part of abdomen whitish.

Male terminalia (Figs 13-17) well sclerotized. Hypandrium about 1.5 times as high as long, processus terminalis approximately straight in lateral view. The latter sclerite with- 
out distinct median incision and ending in a hyaline strip, with irregular edge. There is a pair of distinctly sclerotized dorsal teeth near to the base of processus terminalis. Processus lateralis caudally acute, with several moderately long setae. Anterior apodeme of hypandrium narrowing ventrally, but complete. Gonarcus wide, styli branched, with long, acute posterior branches. Anterior branches of styli do not form a ventral belt below the parameres. (Only a very weak membraneous strip visible here.) Distal part of paramere bent upwards. Processus apicalis forming an acute dorsal projection, which is narrow either in lateral, or in caudal view. Processus ventralis present. Penis represented by a pair of rather short, slightly bent, caudally acute sclerite.

Remarks: Coniopteryx (C.) bidentata sp. $\mathrm{n}$. belongs to Coniopteryx notata group sensu SzIRÁKi 2005, and it is rather close to the Coniopteryx (C.) madagascariensis Meinander, 1974.

The main distinctive features of the new species are:

- processus terminalis of hypandrium without distinct median incision, but with an irregular hyaline caudal edge;

- a pair of dorsal teeth situated near to the base of processus terminalis, instead the sclerotized keel of $C$. madagascariensis;
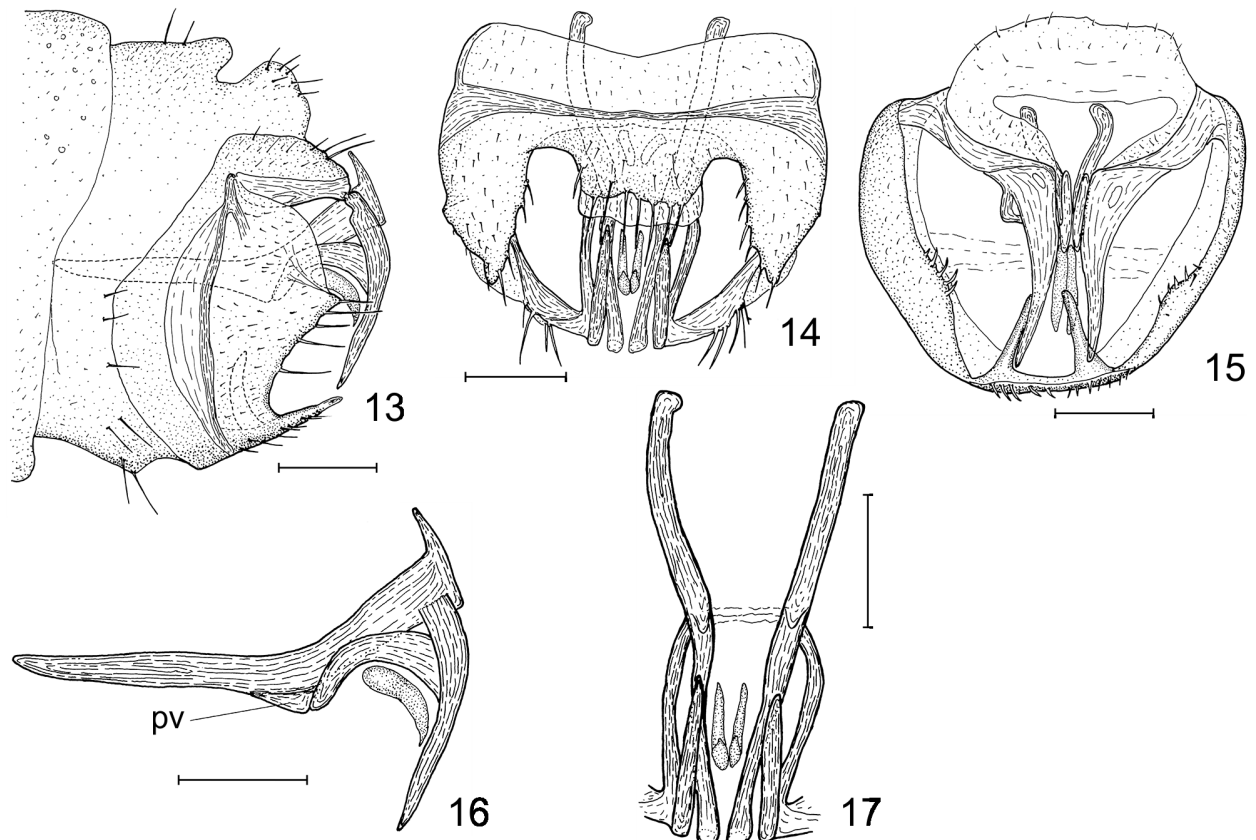

Figs 13-17. Coniopteryx (C.) bidentata sp. n.: $13=$ male terminalia, lateral view, $14=$ male terminalia, ventral view, 15 = male terminalia, caudal view, $16=$ male internal genitalia, lateral view, 17 = male internal genitalia, ventral view. Abbreviation: $\mathrm{pv}=$ processus ventralis of paramere. Scales: $0.04 \mathrm{~mm}$ 
- $\quad$ no transverse plate between the processus lateralis and dorsal inner structure(s) of hypandrium, while in C. madagascariensis it is present;

- paramere has processus ventralis, and bent dorsally;

- number of antennal segments only 23-27;

- basal flagellar segments 2 times, the median ones 1.6 times as wide as long.

Etymology: This new species was named after the inner teeth of the hypandrium.

\section{Coniopteryx (Coniopteryx) corniculata sp. n.}

(Figs 18-23)

Examined material - Holotype: male, Madagascar, Fianarantsoa Province, Ranomafana National Park, Vahiporara at broken bridge, $21^{\circ} 13^{\prime} 34^{\prime \prime}$ S, $47^{\circ} 22^{\prime} 11^{\prime \prime}, 1100 \mathrm{~m}$ a.s.l., 14-21. I. 2002, mountain rain forest, Malaise trap, leg.: HH; deposited in the collection of CAS; CASTYPE number: 20013. Paratypes: 4 males, Madagascar, Fianarantsoa Province, Ranomafana National Park, Belle Vue at Talatakely, $2^{\circ} 15^{\prime} 59^{\prime \prime}$ S, $47^{\circ} 25^{\prime} 13^{\prime \prime}$ E, $1200 \mathrm{~m}$ a.s.l., 16. X - 8. XI. 2001, secondary tropical forest, Malaise trap, leg.: HH; 1 male, same data but 8-15. XI. 2001; 1 male, same data but 28. I - 4. II. 2002; 1 male, same data but 12-19. II. 2002; 3 males, same data, but 31. III - 7. IV. 2002; 1 male, Madagascar, Fianarantsoa Province, Ranomafana National Park, Jirama Water Works, $21^{\circ} 14^{\prime} 55^{\prime \prime}$ S, $47^{\circ} 27^{\prime} 08^{\prime \prime}$ E, 690 m a.s.l., 22-28. XI. 2001, near to the river, Malaise trap, leg. HH; 1 male, Madagascar, Fianarantsoa Province, Ranomafana National Park, radio tower at forest edge, $21^{\circ} 15^{\prime} 03^{\prime \prime} \mathrm{S}, 47^{\circ} 24^{\prime} 26^{\prime \prime} \mathrm{E}$, $1130 \mathrm{~m}$ a.s.l., 16. X - 8. XI. 2001, mixed tropical forest, Malaise trap, leg.: HH; 3 males, same data but 14-21. I. 2002; 2 males, same data but 12-19. II. 2002; 1 male, same data but 31. III - 9. IV. 2002; 1 male, same data but 28. XI - 6. XII. 2002; 1 male, Madagascar, Fianarantsoa Province, Ranomafana National Park, Vahiporara at broken bridge, $21^{\circ} 13^{\prime} 34^{\prime \prime}$ S, 47 $22^{\prime} 11^{\prime \prime}$, $1100 \mathrm{~m}$ a.s.l., 28. XI - 6. XII. 2001, mountain rain forest, Malaise trap, leg.: HH; 1 male, 21-28. I. 2002; 1 male, same data but 28. I - 4. II. 2002; 1 male, same data but 19-26. II. 2002; 2 males, same data but 25. VII - 3. VIII. 2002. Majority of paratypes are deposited in the collection of CAS, while 3 paratype specimens are housed in HNHM.

Description: Length of the body 1.4-1.7 mm. Head capsule and palpi light brown. Sutures on the head dark brown, with black parts. Anterior edge of vertex with a prominent, laterally flattened projection between the antennae. Eyes large, black. Antennae medium brown, 0.9-1.0 mm, 26-28 segmented. Scape nearly as wide as long, or slightly longer than wide. Pedicel in most cases 1.2 times longer than wide, basal flagellar segments 1.5-2 times, median ones 1.3-2 times as wide as long. Pedicel has a rather small, while the first flagellar segment a larger outgrowth subapically, with rather short setae (Fig. 18). The other setae of flagellum moderately long. Ordinary hairs situated in two sparse rings on flagellar segments. Some scale-like hairs are scattered on the pedicel, and in a rather thin whorl apically on the flagellar segments.

Thorax light brown, with dark or medium brown shoulder spots. Sutures and apodemes medium or dark brown, with blackish parts. Legs light brown. Length of the fore wing 1.6-2.0 mm, of hind wing 1.4-1.6 mm. Longitudinal veins light brown, wing membrane brownish. Pregenital part of abdomen pale ochreous. 
Male terminalia (Figs 19-23) medium or dark brown, strongly sclerotized. Hypandrium somewhat longer than high in lateral view. Processus terminalis short, with hyaline apical part, and in ventral view rounded tips. Median incision wide, U-shaped. Processus lateralis strong, very long, and directed caudally. Its setae rather short, with normal (no especially prominent) bases. On the other hand, there is a strong seta (or two setae) at the base of this sclerite. The inner surface of processes laterales are connected by some slightly sclerotized structure. Anterior apodeme of hypandrium blackish, rather narrow, but slightly widened medially. Gonarcus with widened basal part, and without distinct caudal projection. Stylus forked; its outer branch narrow, pointed, and turned fowards rather sharply, while the inner branch wide. The bridge between the two inner branches well sclerotized and connected to the distal part of paramere with a strip detectable in caudal view. Besides, above the parameres there is a slightly sclerotized distal belt between the two inner branches of styli. (Not detectable in lateral view.) Paramere strong, with a minute processus ventralis. Processus apicalis large; its ventro-caudal angle obtuse. Penis sclerite consists of two moderately chitinized, slightly bent rods, supported by some membraneous structure.

Remarks: Coniopteryx (C.) corniculata sp. n. belongs to the Coniopteryx lobifrons group sensu SzIRÁKI (2005), and - because of the similar structure of the large part of hypandrium - resembles somewhat to Coniopteryx (C.) malgasensis Sziráki, 2015.
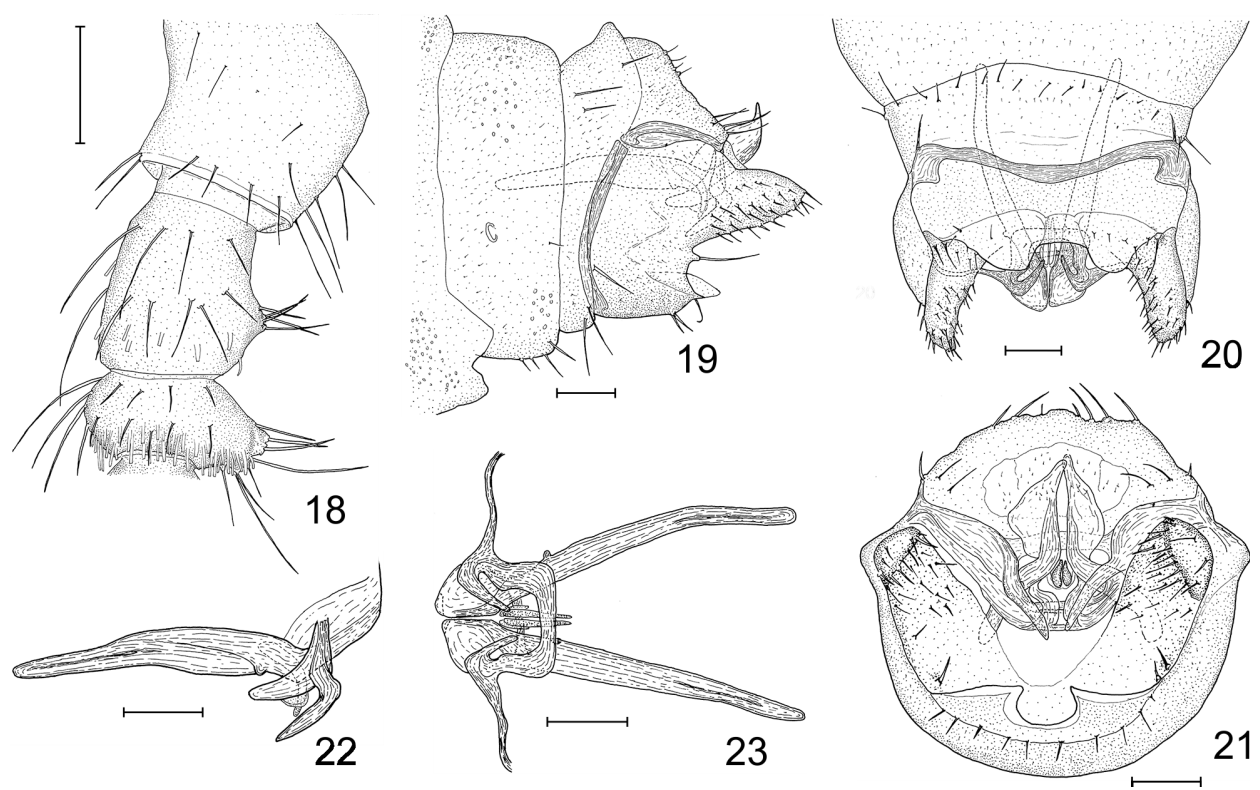

Figs 18-23. Coniopteryx (C.) corniculata sp. n.: $18=$ basal part of antenna, $19=$ male terminalia, lateral view, $20=$ male terminalia, ventral view, $21=$ male terminalia, caudal view, $22=$ male internal genitalia, lateral view, $23=$ male internal genitalia, ventral view. Scales: $0.04 \mathrm{~mm}$ 
The main distinctive features of the new species are:

- apical whorl of scale-like hairs on flagellar segments thin;

- processus lateralis of hypandrium strong and very long;

- $\quad$ bases of the setae on processus lateralis normal (not prominent especially);

- ventro-caudal angle of processus apicalis obtuse;

- bridge between the two inner branches of stylus connected to the distal part of paramere;

- $\quad$ there is a slightly sclerotized distal belt above the parameres.

Etymology: The new species named after the shape of the male teminalia in ventral or dorsal view (corniculum $=$ little horn in Latin).

\section{Coniopteryx (Coniopteryx) crenata sp. $\mathrm{n}$.}

(Figs 24-29)

Examined material - Holotype: male, Madagascar, Antsiranana Province, Ampasi-

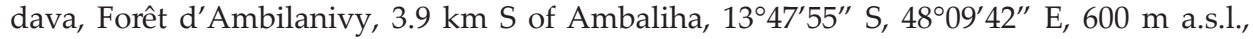
4-9. III. 2001, rain forest, Malaise trap, leg.: F, G et al.; deposited in the collection of CAS; CASTYPE number: 20014. Paratypes: 3 males, Madagascar, Antananarivo Province, 3 km NE of Andranomay, $11.5 \mathrm{~km}$ of Anjororobe, $18^{\circ} 28^{\prime} 24^{\prime \prime}$ S, 47 $57^{\prime} 36^{\prime \prime} \mathrm{E}, 1300 \mathrm{~m}$ a.s.l., 5-13. XII. 2000, mountain rain forest, Malaise trap, leg. F, G et al. Two of the paratypes deposited in the collection of CAS, while one is housed in HNHM.

Description: Length of the body 1.4-1.6 mm. Head capsule light brown, palpi pale ochreous. Anterior edge of vertex with a prominent, laterally flattened projection between the antennae. Eyes moderately large, black. Antennae yellowish brown, 0.9-1.2 mm, 28-31 segmented. Scape slightly wider than long, pedicel somewhat longer than wide. Flagellar segments 1-2 and 11-18 about two times as wide as long, segments 6-7 three or four times as wide as long, while the segments $21-26$ about as long as wide. Pedicel has a small, while the first flagellar segment a highly elongated, well separated outgrowth subapically, with relatively short setae (Fig. 24). The regular setae of flagellum moderately long. Besides, this type of setae of the first flagellar segment has a prominent base, separated from the long outgrowth. Ordinary hairs are in two rather irregular rings on pedicel and on flagellar segments. Scale-like hairs are dispersed sparsely on large part of pedicel, and situated in a dense, broad whorl apically on the flagellar segments.

Thorax, legs and pregenital part of abdomen pale ochreous. Shoulder spots light brown, thoracal sutures and apodemes mostly light or medium brown. Length of the fore wing 1.8-2.2 mm, of hind wing 1.3-1.5 mm. Longitudinal veins light yellowish brown, wing membrane hyaline or light brown.

Male terminalia (Figs 25-29) normally sclerotized, light or medium brown. Ventral apodeme of gonarcus and anterior apodeme of hypandrium medium brown. Hypandrium longer than high in lateral view. Processus terminalis very narrow and acute in lateral view, and with tapering subtriangular endings in ventral view. Median incision narrow u-shaped and deep, with a small subapical inner outgrowth, and with a hyaline median 
edge. Processus lateralis elongated caudally; its several caudal setae have extraordinarily large bases, giving a crenated appearance to this sclerite. Otherwise, setae of processus lateralis are rather short. Ventral part of the anterior apodeme of the hypandrium moderately broad and slightly bent backward, while its lateral parts narrow. Ventral apodeme of gonarcus thin. Stylus forked; its outer branch distinctly curved forwards. The two - basally very broad - inner branches forming a distinct ventral bridge below the parameres. Paramere moderately long, with a lateral view sinuous anterior part. Processus ventralis of paramere strong. Processus apicalis rather large, with a dorsal part pointed in lateral view, and with a large - in caudal view sharp - caudal angle. Dorsal part of processus apicalis in caudal view rounded dorsally. The penis sclerite consists of two moderately chitinized, slightly bent rods.

Remarks: Coniopteryx (C.) crenata sp. n. belongs to the Coniopteryx lobifrons group sensu SzIRÁKI (2005), and - because of the similar basic structure of hypandrium and paramere - it is close to Coniopteryx (C.) malgasensis Sziráki, 2015.
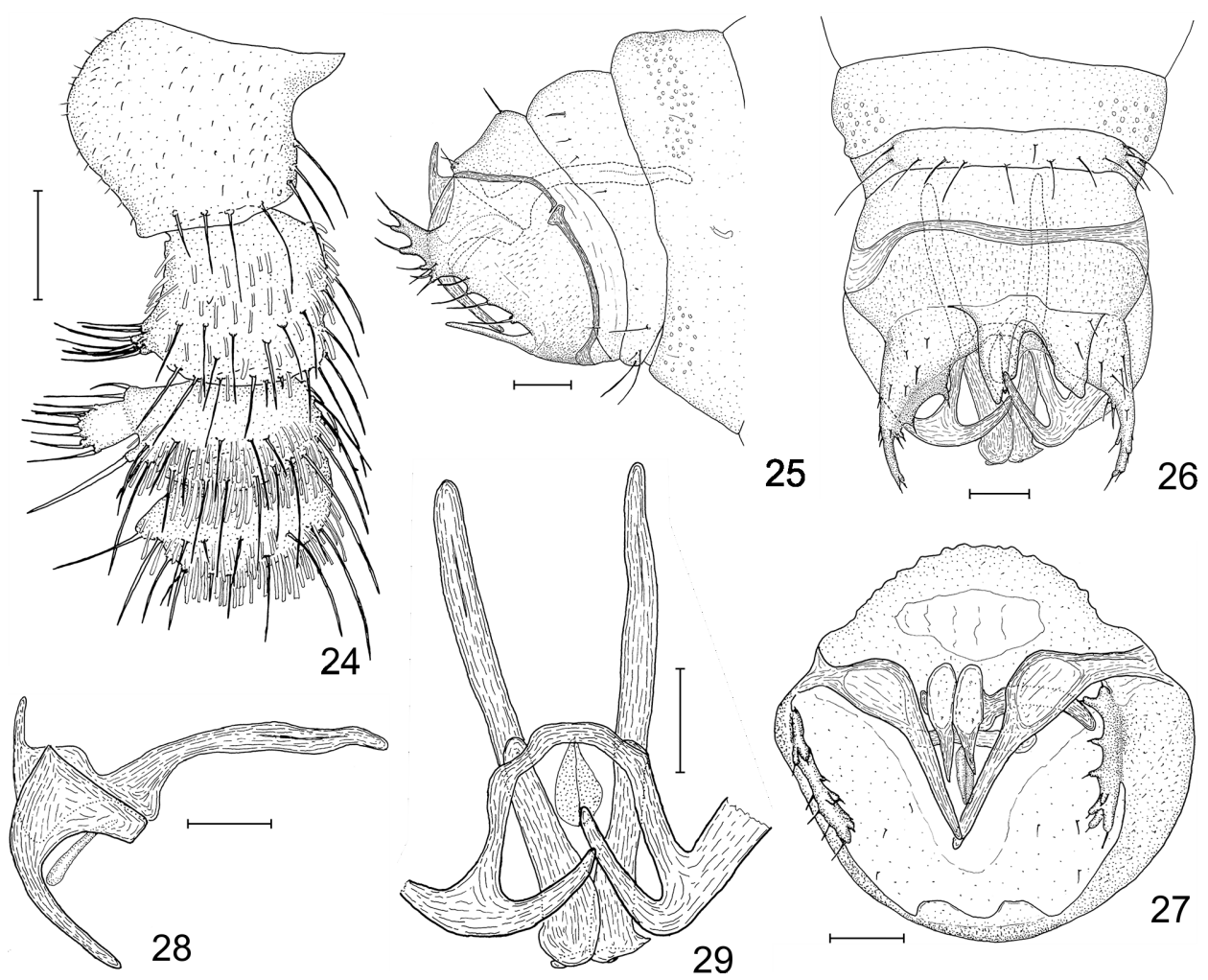

Figs 24-29. Coniopteryx (C.) crenata sp. n.: $24=$ basal part of antenna, $25=$ male terminalia, lateral view, $26=$ male terminalia, ventral view, $27=$ male terminalia, caudal view, $28=$ male internal genitalia, lateral view, $29=$ male internal genitalia, ventral view. Scales: $0.04 \mathrm{~mm}$ 
The main distinctive features of the new species are:

- $\quad$ outgrowth of the first flagellar segment well separated and extremely long;

- bases of some setae on processus lateralis extraordinarily large;

- median incision of processus terminalis of hypandrium deep;

- processus terminalis narrow and acute in lateral view;

- processus ventralis of paramere strong;

- dorsal part of processus apicalis rounded dorsally in caudal view.

Etymology: The new species is named after the crenated (almost toothed) caudal edge of processus lateralis of hypandrium.

\section{Coniopteryx (Coniopteryx) fianarantsoana sp. $\mathrm{n}$.}

(Figs 30-34)

Examined material - Holotype: male, Madagascar, Fianarantsoa Province, Ranomafa-

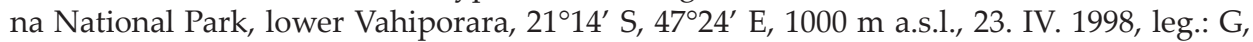
K, P, MR, JR, JS \& U; deposited in the collection of CAS; CASTYPE number: 20015 . Paratypes: 1 male, Madagascar, Antananarivo Province, $3 \mathrm{~km}$ NE of Andranomay, $11.5 \mathrm{~km}$ of Anjororobe, $18^{\circ} 28^{\prime} 24^{\prime \prime}$ S, 47 57'36" E, $1300 \mathrm{~m}$ a.s.l., 5-13. XII. 2000, mountain rain forest, Malaise trap, leg. F, G et al.; 1 male, Madagascar, Fianarantsoa Province, Ranomafana National Park, Belle Vue at Talatakely, $21^{\circ} 15^{\prime} 59^{\prime \prime}$ S, 47 $25^{\prime} 13^{\prime \prime}$ E, $1200 \mathrm{~m}$ a.s.1.,12-19. II. 2002, secondary tropical forest, Malaise trap, leg.: HH; 1 male, Madagascar, Fianarantsoa

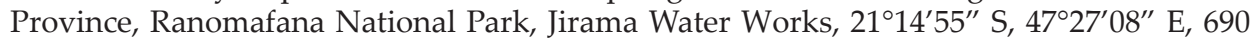
$\mathrm{m}$ a.s.l., 16. X - 8. XI. 2001, near to the river, Malaise trap, leg. HH; 1 male, Madagascar, Fianarantsoa Province, Ranomafana National Park, Vahiporara, $21^{\circ} 13^{\prime} 34^{\prime \prime}$ S, 47 $22^{\prime} 11^{\prime \prime}$ E, 1110 m. a.s.l., 4-12. II. 2002, mountain rainforest, Malaise trap, leg.: HH;1 male, Madagascar, Fianarantsoa Province, Ranomafana National Park, Vahiporara at broken bridge, $21^{\circ} 13^{\prime} 34^{\prime \prime} \mathrm{S}, 47^{\circ} 22^{\prime} 11^{\prime \prime}, 1100 \mathrm{~m}$ a.s.l., 15-21. XII. 2001, mountain rain forest, Malaise trap, leg.: HH; 1 male, same data but 24. XII. 2001-2. I. 2002; 1 male, same data but 4-12. II. 2002. Five of the paratypes deposited in the collection of CAS, one is housed in HNHM. It should be mentioned that almost all of the examined specimens were in more or less poor condition, with somewhat softened sclerotization.

Description: Length of the body 1.5-1.8 mm. Head capsule and palpi pale ochreous. Anterior edge of vertex with a moderately large, laterally flattened projection between the antennae. The eyes seem to be variable in size, being moderately or very large. Antennae (Fig. 30) light brown, 1.0-1.2 mm, 27-32 segmented. Scape slightly wider than long, pedicel about 1.5 times longer than wide. Basal flagellar segments cca. two times as wide as long, while the median ones are rather variable: about 1.5-2 times wider than long. First flagellar segment basally has a small inner outgrowth consist of merged outstanding bases of moderately long setae, and there are some other setae with prominent bases around the regular seta. The latter group of setae is separated clearly from the basal outgrowth. Pedicel without any outgrowth. Regular setae are relatively short, and situated on prominent bases on 2-8 flagellar segments. Ordinary hairs are in an apical ring on the scape, in two 
somewhat irregular rings on pedicel, and situated rather irregularly on flagellar segments. Scale-like hairs are dispersed sparsely on large part of pedicel and on the basal half of the first flagellar segment, and arranged in a broad whorl on the apical half of the flagellomeres (including the first one).

Thorax, legs and pregenital part of abdomen pale ochreous. Shoulder spots and thoracal sutures and apodemes light or medium brown. Length of the fore wing 1.9-2.3 mm, of hind wing 1.4-1.6 mm. Wing membrane hyaline, or has a very light brownish tint.

Male terminalia (Figs 31-34) of the examined specimens medium brown. Hypandrium in lateral view about as long as high. Apparent processus terminalis of hypandrium very short, pointed in lateral and rounded in ventral view. However, dorsally of this sclerite there is a paired hyaline, but distinctly sclerotized inner structure, which surely is homologous with the inner structure of some other species (e. g.: Coniopteryx (C.) auricularia), but may contain also some parts of the original processus terminalis because of the well developed hairs on its surface. This inner structure in lateral view pointed or tapering, in ventral view rounded. (A small sharp unevenness - visible in lateral or in ventral view may be present on it.) True median incision is absent, but there is a rounded „incision" between the two parts of the above mentioned inner structure. Processus lateralis prominent. Its setae rather short, with moderately developed bases. Anterior apodeme of hypandrium and ventral apodeme of gonarcus narrow. Stylus forked; its outer branch strongly curved forwards, in lateral view serrated finely and ending in 2-3 small teeth. The inner branches
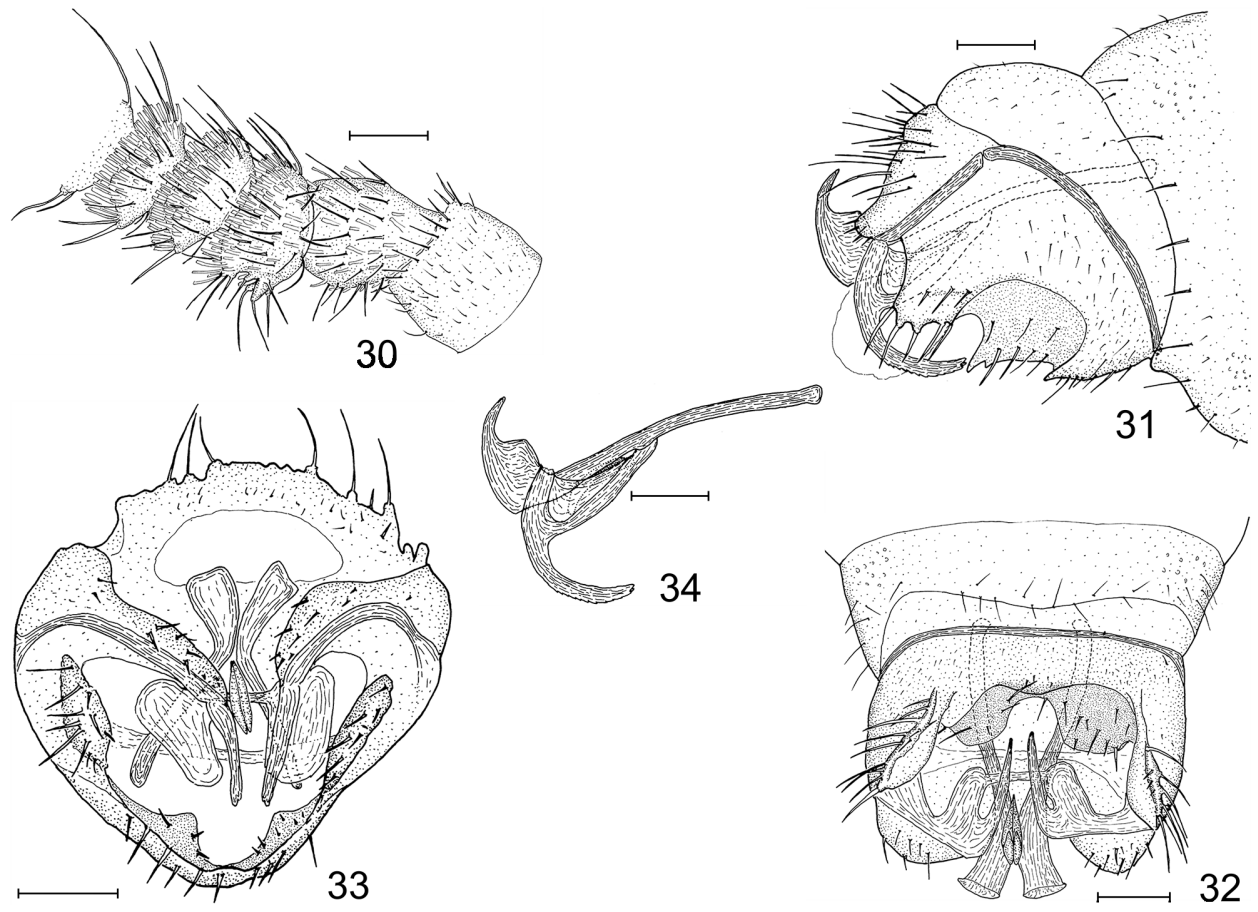

Figs 30-34. Coniopteryx (C.) fianarantsoana sp. n.: $30=$ basal part of antenna, $31=$ male terminalia, lateral view, 32 = male terminalia, ventral view, 33 = male terminalia, caudal view, $34=$ male internal genitalia, lateral view. Scales: $0.04 \mathrm{~mm}$ 
of styli lobe-like in ventral or caudal view, and connected by a rather weak bridge below the parameres. Besides, a membraneous connecting belt situated dorsally of parameres. Paramere is rather long, and slightly bent. Processus apicalis of this sclerite moderately large; its dorsal ending hooked in lateral- and subtriangular in caudal view. Processus ventralis indistinct. Penis sclerite consists of two slightly bent rods.

Remarks: Coniopteryx (C.) fianarantsoana sp. n. belongs to the Coniopteryx lobifrons group sensu SzIRÁki (2005), and - because of the similar arrangement of hypandrium (including the presence of a well developed inner structure) and the similarity of paramere - it is close to Coniopteryx (C.) auricularia sp. n.. Besides, because the rather similar construction of the inner structure of hypandrium C. fianarantsoana seems to be closely related to Coniopteryx (C.) geniculata sp.n. Moreover, some important features of male genitalia resembles to Coniopteryx (C.) harinhalai sp. n. (see ahead).

Regarding C. auricularia the main distinctive features of Coniopteryx (C.) fianarantsoana sp. n. are:

- basal outgrowth of the first flagellar segment small, and it appears as fused bases of setae;

- $\quad$ around the apically situated regular seta of the first flagellar segment there are some other setae with outstanding base. The basal and apical groups of setae are clearly separated;

- processus terminalis of hypandrium extremely short;

- $\quad$ inner structure of hypandrium is paired, in lateral view pointed or tapering sclerite;

- $\quad$ outer branch of stylus finely serrated, and endings in small teeth;

- inner branch of stylus lobe-like in lateral and in caudal view;

- $\quad$ there is not an, in ventral view U-shaped, additional sclerite around the penis (which present in C. auricularia);

- processus apicalis of paramere subtriangular in caudal view. (For separation from C. geniculata sp. n. and from C. harinhalai sp. n. see in the description of the latter species.)

Etymology: The new species is named after the Fianarantsoa Province, where the holotype and three of the four paratypes were collected.

Coniopteryx (Coniopteryx) geniculata sp. n.

(Figs 35-40)

Examined material - Holotype: male, Madagascar, Antsiranana Province, Montagne d'Ambre National Park, $12^{\circ} 30^{\prime} 52^{\prime \prime}$ S, 49¹0'53" E, 960 m a.s.l., 19. III-5. IV. 2001, Malaise trap, leg.: HH; deposited in the collection of CAS; CASTYPE number: 20016. Paratypes: 6 males, same data as holotype; 1 male, Madagascar, Antsiranana Province, $7 \mathrm{~km}$ N of Jof- 
freville, $12^{\circ} 20^{\prime} \mathrm{S}, 4^{\circ} 15^{\prime} \mathrm{E}, 360 \mathrm{~m}$ a.s.l., 6-20. III. 2001, dry forest, Malaise trap, leg.: HH; 1 male, same data but 27. IV - 13. V. 2001; 1 male, Madagascar, Antsiranana Province, Marojejy National Park, at Manantenina River, $14^{\circ} 26^{\prime} 12^{\prime \prime}$ S, 49 $46^{\prime} 30^{\prime \prime}$ E, 450 m a.s.l., 12-25. XI. 2003, rain forest, Malaise trap, leg.: F et al., 1 male, Madagascar, Antsiranana Province, Montagne d'Ambre National Park, 12³0'52" S, 49¹0'53" E, 960 m a.s.1., 26-29. I. 2001, Malaise trap, leg.: I, ES \& HH; 1 male, Madagascar, Antsiranana Province, Montagne d'Ambre National Park, $12^{\circ} 31^{\prime}$ S, $49^{\circ} 11^{\prime}$ E, 975 m a.s.l., 21-25. I. 2001, Malaise trap, leg.: I, S \& HH; 1 male, Madagascar, Antsiranana Province, Montagne d'Ambre National Park, $12^{\circ} 31^{\prime} 13^{\prime \prime}$ S, 49 ${ }^{\circ} 10^{\prime} 45^{\prime \prime}$ E, $1125 \mathrm{~m}$ a.s.1., 29. I - 11. II. 2001, Malaise trap, leg.: HH; 1 male, Madagascar, Fianarantsoa Province, Ranomafana National Park, radio tower at forest edge, $21^{\circ} 15^{\prime} 03^{\prime \prime}$ S, 47 $24^{\prime} 26^{\prime \prime}$ E, $1130 \mathrm{~m}$ a.s.1., 16. X - 8. XI. 2002, mixed tropical forest, Malaise trap, leg.: $\mathrm{HH}$; 1 male, Madagascar, Toamasina Province, $7 \mathrm{~km}$ SE of Andasibe National Park headquarters, $18^{\circ} 57^{\prime} 46^{\prime \prime}$ S, 48 $27^{\prime} 10^{\prime \prime}$ E, 1050 m a.s.l., 9-23. III. 2001, tropical forest, Malaise trap, leg.: HH; 1 male, same data but 7-9. IV. 2001; 1 male, same data but 9-23. IV. 2001; 1 male, Madagascar, Toamasina Province, botanic garden near to entrance to Andasibe National Park, $18^{\circ} 55^{\prime} 35^{\prime \prime}$ S, 48 $24^{\prime} 28^{\prime \prime}$ E, $1025 \mathrm{~m}$ a.s.l., 23-30. IV. 2001, tropical forest, Malaise trap, leg.: HH; 1 male, same data but 21. V - 4. VI. 2001; 1 male, same data but 29. VI - 14. VII. 2001; 2 males, same data but 8-16. X. 2001; 1 male, same data but 7-16. XI. 2001. Majority of paratypes deposited in the collection of CAS, while 3 paratype specimens are housed in HNHM.

Description: Length of the body 1.3-1.6 mm. Head capsule and palpi pale ochreous. Anterior edge of vertex with a large, laterally flattened projection between the antennae. Eyes rather large, black. Antennae (Fig. 35) light or medium brown, $0.8-1.0 \mathrm{~mm}, 27-28$ segmented. Scape slightly wider than, or as wide as long, pedicel about 1.3 times longer than wide. Basal flagellar segments about 3 times wider than long, while in the apical half of the antennae most of the segments 2 times wider than long. (In some cases the 1-3 flagellar segments have similar length/width proportions as the apical ones.) Pedicel with a small, the first flagellar segment with a considerable setose outgrowth. Regular setae are moderately long. These setae situated on prominent bases in the case of the 2-8 flagellar segments. Ordinary hairs are in an apical ring on the scape, apically in a ring but otherwise irregularly on pedicel, and in two more or less irregular rings on flagellar segments. Scalelike hairs are dispersed rather densely on large part of pedicel, and arranged in a narrow apical whorl on the flagellomeres.

Thorax and legs light brown, thoracal sutures and apodemes medium or dark brown, shoulder spots medium brown. Length of the fore wing 1.7-1.8 $\mathrm{mm}$, of hind wing 1.2-1.5 $\mathrm{mm}$. Wing membrane light brown, but along the veins hyaline. Pregenital part of the abdomen pale ochreous.

Male terminalia (Figs 36-40) well sclerotized, dark or medium brown. Hypandrium in lateral view somewhat higher than long. Processus terminalis moderately long, with pointed, laterally curved caudal endings. Median incision of processus terminalis broadly v-shaped, with rounded anterior line. A pair of hyaline, but well sclerotized, prominent, knot-like inner structure is attached dorsally to the processus terminalis of hypandrium. Processus lateralis rather large, subtriangular, and directed caudally. Its setae moderately long, without prominent bases. Anterior apodeme of hypandrium narrow, but widened medially. Ventral apodeme of ectoproct well developed. Stylus forked; its outer branch moderately long, directed ventrally, and serrated very finely. The inner branches of styli construct a rather complicated looped structure (visible most clearly in caudal view), which 
has a band supporting the penis sclerites ventrally. Besides, a moderately sclerotized dorsal arch is connected to this band above the penis. Paramere distinctly curved, and has a broad caudal and a relatively narrow proximal part. Processus apicalis has a dorsal tip tapering in caudal, pointed in lateral view, and a small, acute inner projection. Processus ventralis of paramere distinctly visible. Penis consists of two sclerites, with ventro-caudally tapering, dorso-proximally flattened endings.

Remarks: Coniopteryx (C.) geniculata sp. $\mathrm{n}$. belongs to the Coniopteryx lobifrons group sensu SzIRÁKI (2005), and - because of the prominent paired inner structure of hypandrium and the finely serrated outer branch of the stylus - it related most closely to Coniopteryx (C.) fianarantsoana sp. n..

The main distinctive features of Coniopteryx (C.) geniculata sp. n. are:

- presence of a setose inner outgrowth on apical half of pedicel;

- the setose outgrowth of the first flagellar segment large and homogeneous;
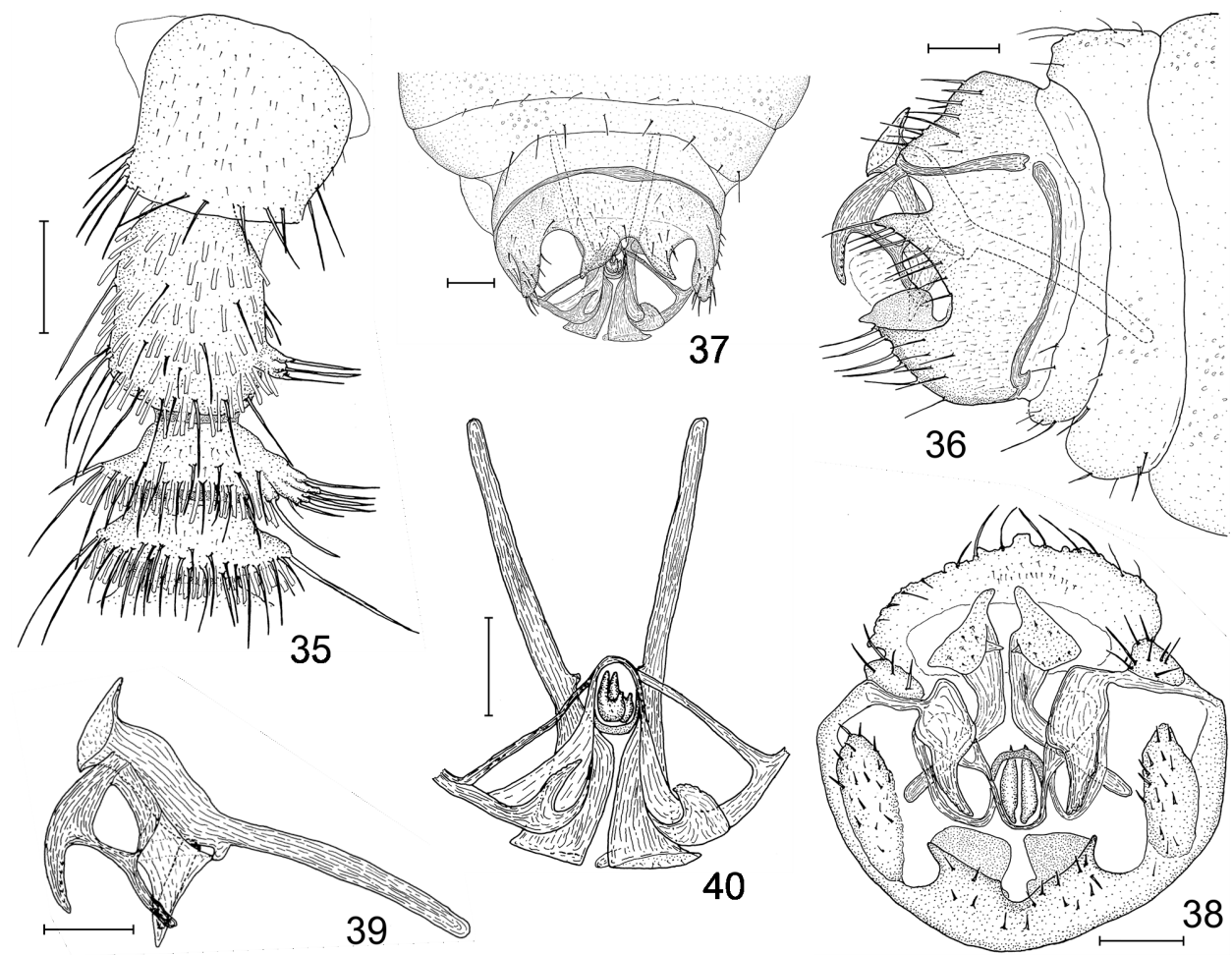

Figs 35-40. Coniopteryx (C.) geniculata sp. n.: 35 = basal part of antenna, $36=$ male terminalia, lateral view, $37=$ male terminalia, ventral view, $38=$ male terminalia, caudal view, $39=$ male internal genitalia, lateral view, $40=$ male internal genitalia, ventral view. Scales: $0.04 \mathrm{~mm}$ 
- processus terminalis of hypandrium moderately long, with pointed, laterally curved caudal endings;

- inner structure of hypandrium rounded in lateral view;

- $\quad$ outer branch of the stylus relatively short, and directed ventrally;

- inner branch of stylus has a special looped structure;

- $\quad$ paramere in ventral view distinctly curved near to well detectable processus ventralis;

- $\quad$ processus apicalis of paramere has a small inner projection and a dorsal tip tapering in caudal view.

Etymology: The new species is named after the prominent knot-like internal structure of hypandrium $(\mathrm{knot}=$ geniculum in Latin).

\section{Coniopteryx (Coniopteryx) harinhalai sp. $\mathrm{n}$.}

$$
\text { (Figs 41-46) }
$$

Examined material - Holotyte: male, Madagascar, Fianarantsoa Province, Ranomafana National Park, Vahiporara at broken bridge, $21^{\circ} 13^{\prime} 34^{\prime \prime}$ S, $47^{\circ} 22^{\prime} 11^{\prime \prime}, 1100 \mathrm{~m}$ a.s.l., $14-$ 21. I. 2002, mountain rain forest, Malaise trap, leg.: HH; deposited in collection of CAS; CASTYPE number: 20017. Paratypes: 2 males, same data as holotype but 28 . XI -6 . XII. 2001; 1 male, same data but 6-15. XII. 2001; 1 male, same data but 6-15. V. 2002; 1 male, same data but 22-28. XI. 2002; 1 male, Madagascar, Fianarantsoa Province, Forêt d' Am-

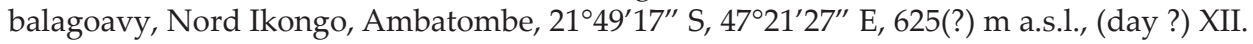
2000, Malaise trap, leg.: HH \& I; 3 males, Madagascar, Fianarantsoa Province, Ranomafana National Park, Belle Vue at Talatakely, $2^{\circ} 15^{\prime} 59^{\prime \prime}$ S, $47^{\circ} 25^{\prime} 13^{\prime \prime}$ E, $1200 \mathrm{~m}$ a.s.l., 16. X - 8. 11. 2001, secondary tropical forest, Malaise trap, leg.: HH; 1 male, same data but 24. XII. 2001 - 2. I. 2002; 1 male, same data but 21-28. I. 2002; 1 male, same data but 26-31. III. 2002; 1 male, same data but 7-14. IV. 2002; 1 male, Madagascar, Fianarantsoa Province, Ranomafa-

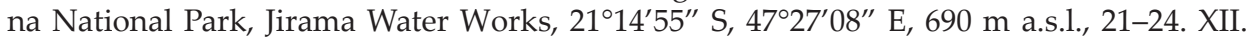
2001, near to the river, Malaise trap, leg. HH; 2 males, Madagascar, Fianarantsoa Province, Ranomafana National Park, radio tower at forest edge, $21^{\circ} 15^{\prime} 03^{\prime \prime}$ S, $47^{\circ} 24^{\prime} 26^{\prime \prime}$ E, $1130 \mathrm{~m}$ a.s.l., 16. X - 8. XI. 2001, mixed tropical forest, Malaise trap, leg.: HH; 1 male, Madagascar, Fianarantsoa Province, Ranomafana National Park, Talatakely, $21^{\circ} 15^{\prime}$ S, $47^{\circ} 25^{\prime}$ E, $900 \mathrm{~m}$ a.s.l., 16. IV. 1998, leg.: G, K, P, MR, JS \& U. Majority of paratypes are deposited in the collection of CAS, while 3 paratype specimens are housed in HNHM.

Description: Length of the body 1.3-1.7 mm. Head capsule and palpi medium or light brown. Anterior edge of vertex with a large, laterally flattened projection between the antennae. Eyes moderately large, black. Antennae (Fig. 41) dark brown, 0.9-1.1 mm, usually 27 , rarely 28 segmented. Scape 1.1-1.3 times wider than long, pedicel slightly longer than wide. Length of the flagellar segments rather variable. Therefore, basal flagellar segments 1.4-2.3 times wider than long, while in the apical half of antennae most of the segments 1.4-2 times wider than long. Pedicel has only a slightly emerging setose outgrowth, while the first flagellar segment has a large, prominent one. Regular setae of flagelomeres and the setae of the outgrowths are relatively short. The rather long ordinary hairs distributed 
irregularly on pedicel, and situated in two irregular rings on flagellar segments. Scale-like hairs dispersed on considerable part of pedicel, and arranged in a dense apical whorl on flagellomeres.

Thorax pale ochreous, legs medium brown, shoulder spots, as well as the thoracal sutures and apodemes dark brown. Length of the fore wing 1.6-2.0 mm, of hind wing 1.3-1.7 $\mathrm{mm}$. Wing membrane light brown, longitudinal veins and the basal $\mathrm{M}-\mathrm{Cu}$ cross vein medium brown. Pregenital part of the abdomen pale ochreous.

Male terminalia (Figs 42-46) well sclerotized, dark brown. Hypandrium in lateral view slightly higher than long. Processus terminalis very short, truncated and broad. Median incision absent. A pair of moderately emerging inner structure is attached to the processus terminalis of hypandrium. The two parts of this structure is connected by a low crest. Processus lateralis bulky subtriangular, and directed caudally. Its setae moderately long, without prominent bases. Anterior apodeme of hypandrium moderately broad. Its dorsal part is continued in a ventro-caudally directed section. Ventral apodeme of ectoproct well sclerotized, and its anterior part distinctly widened. Stylus forked; its outer branch distinctly curved forwards, while the wide, lobular inner branch situated laterally and ventrally of parameres. Besides, the two inner branches appear connected by a narrow subapical belt. Paramere bent evenly in lateral, but straight in ventral view. Processus apicalis deeply bifid in lateral view, and the larger caudal branch of this process clearly triangular in caudal view. Processus ventralis of paramere present, but very small. Penis consists of two narrow, in lateral view hooked, ventrally tapering sclerites.
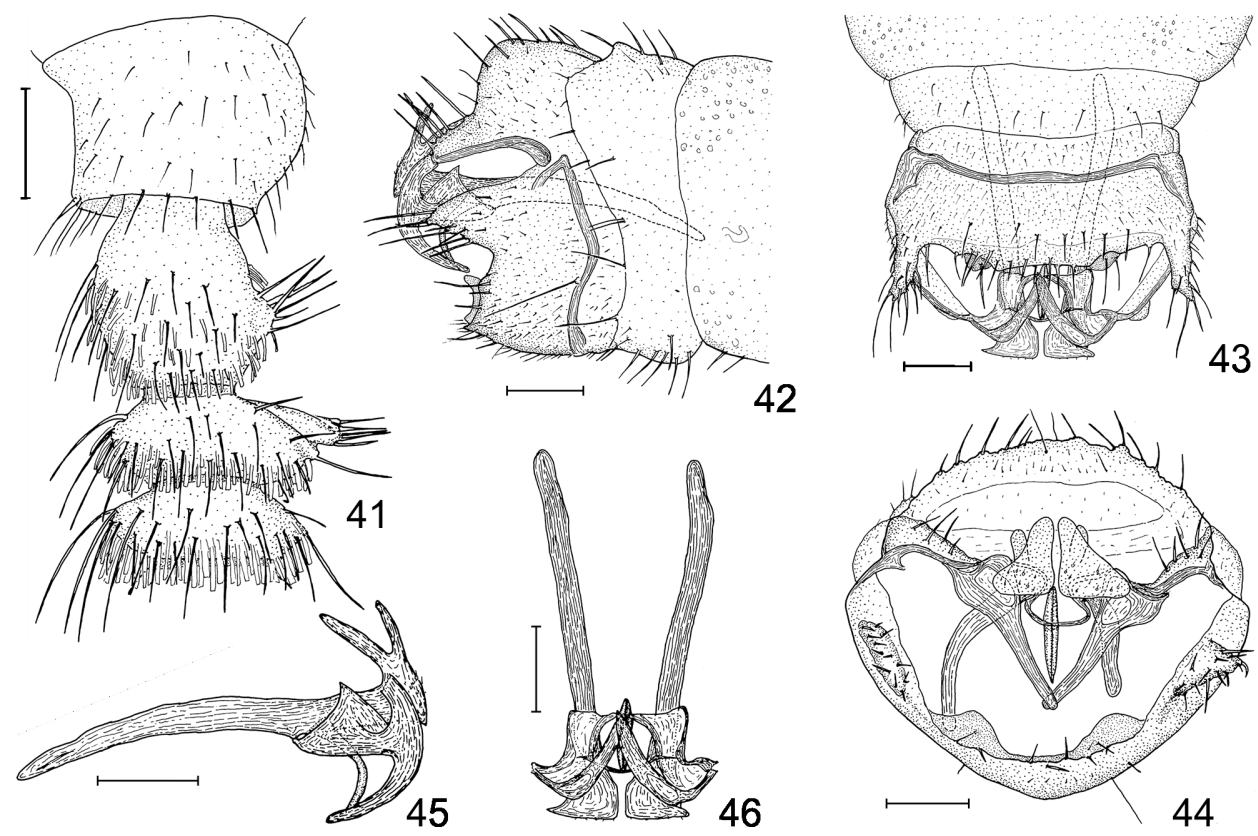

42
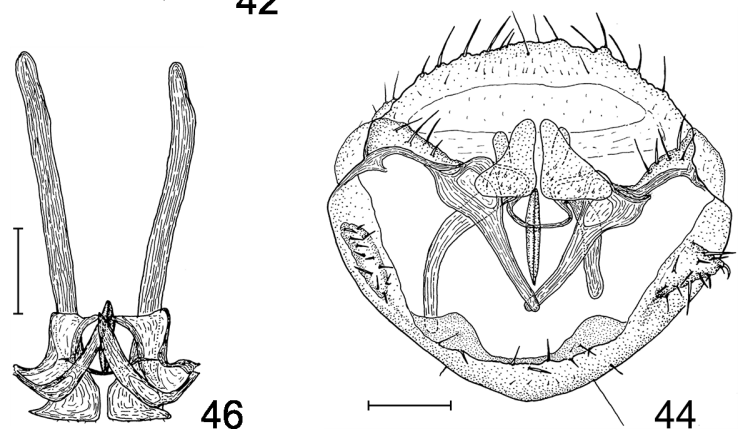

Figs 41-46. Coniopteryx (C.) harinhalai sp.n.: $41=$ basal part of antenna, $42=$ male terminalia, lateral view, $43=$ male terminalia, ventral view, $44=$ male terminalia, caudal view, $45=$ male internal genitalia, lateral view, $46=$ male internal genitalia, ventral view. Scales: $0.04 \mathrm{~mm}$ 
Remarks: Coniopteryx (C.) harinhalai sp. $\mathrm{n}$. belongs to the Coniopteryx lobifrons group sensu Sziráki (2005), and - because of the very short processus terminalis, the presence of the inner structure of hypandrium and the curving forwards outer branch of the stylus - it most closely related to Coniopteryx (C.) fianarantsoana sp. n., but it resembles somewhat to Coniopteryx (C.) geniculata sp. n. also.

Regarding C. fianarantsoana the main distinctive features of Coniopteryx (C.) harinhalai sp. n. are:

- presence of a small setose outgrowth on pedicel;

- $\quad$ broad, truncated and very short processus terminalis of hypandrium;

- relatively small inner structure of hypandrium;

- $\quad$ simple edge and ending of outer branch of stylus;

- $\quad$ in lateral view deeply bifid processus apicalis of paramere.

As C. geniculata regards C. harinhalai sp. n. clearly separable from it by the

- $\quad$ very short and broad processus terminalis of hypandrium;

- absence of median incision;

- $\quad$ the deeply bifid processus apicalis of paramere.

Etymology: The new species is dedicated to Mr. Rasolondalao Harin'Hala (Schlinger Foundation, Madagascar), collector of the majority of the examined Madagascan coniopterygid material.

\section{Coniopteryx (Coniopteryx) ihorombeana sp. n.} (Figs 47-51)

Examined material - Holotype: male, Madagascar, Fianarantsoa Province, Ranomafa-

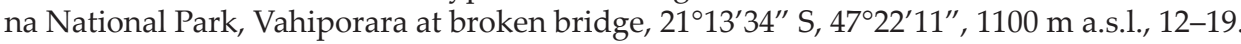
III. 2002, mountain rain forest, Malaise trap, leg.: HH; deposited in the collection of CAS; CASTYPE number: 20018. Paratypes: 1 male, Madagascar, Antsiranana Province, Montagne d'Ambre National Park, 12³0’52" S, 49¹0’53" E, 960 m a.s.1., 19. III - 5. IV. 2001, Malaise trap, leg.: I, ES \& HH; 1 male, Madagascar, Antsiranana Province, Montagne d'Ambre

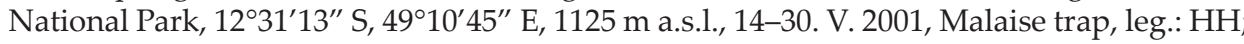
1 male, Madagascar, Antsiranana Province, Sakalava Beach, 12 $15^{\prime} 46^{\prime \prime}$ S, 49 $23^{\prime} 51^{\prime \prime}$ E, 10 m a.s.l., (day?). VIII - (day?). IX. 2001, dwarf littoral forest, Malaise trap, leg.: HH; 1 male, Madagascar, Fianarantsoa Province, near to Isalo National Park, at a stream E of Interpretive Center, $22^{\circ} 37^{\prime} 36^{\prime \prime}$ S, $45^{\circ} 21^{\prime} 29^{\prime \prime}$ E, $750 \mathrm{~m}$ a.s.l., 21-29. XII. 2001, open area, Malaise trap, leg.: HH; 1 male, same data but 19-26. I. 2001; 1 male, same data but 10-15. VII. 2002; 1 male, Madagascar, Fianarantsoa Province, near to Isalo National Park, E of Interpretive Center, $22^{\circ} 37^{\prime} 36^{\prime \prime}$ S, $45^{\circ} 21^{\prime} 29^{\prime \prime}$ E, $885 \mathrm{~m}$ a.s.l., 17-25. XI. 2001, dry stream bed, Malaise trap, leg.: HH; 1 male, same data but 30. XI - 7. XII. 2001; 1 male, same data but 16-21. XII. 2001; 1 male, same data but 13-19. I. 2002; 1 male, same data but 26. I - 3. II. 2002; 1 male, same data but 3-10. II. 2002; 1 male, same data but 17-24. II. 2002; 1 male, same data but 13-20. V. 2002; 1 male, Madagascar, Toamasina Province, $7 \mathrm{~km}$ SE of Andasibe National Park headquarters, $18^{\circ} 57^{\prime} 46^{\prime \prime}$ S, $48^{\circ} 27^{\prime} 10^{\prime \prime}$ E, 1050 m a.s.l., 9-23. III. 2001, tropical forest, Malaise 
trap, leg.: HH. Majority of paratypes deposited in the collection of CAS, while 3 paratype specimens are housed in HNHM.

Description: Length of the body 1.3-1.6 mm. Genae light brown, other parts of head capsule pale ochreous. Eyes relatively small, black or brownish. Antennae very light yellowish-brown, 1.0-1.2 mm, 27-32 (most frequently 28) segmented. Scape about as wide as long, pedicel slightly (1.2-1.3 times) longer than wide. The relative length of the flagellar segments is rather variable: those 1.3-1.8 times wider than long in the basal half of flagellum and 1.1-1.4 times wider than long in the apical half. Ordinary hairs seems to be in a dorsal group on the scape, mostly in two rings on pedicel, while in a single, rather irregular ring on flagellar segments. Scale-like hairs are scattered on a considerable part of pedicel, and arranged in a dense apical whorl on flagellar segments. Inner setae of flagellar segments rather long. (About as long as the width of the segments in the apical half of flagellum.) Palpi pale ochreous.

Thorax yellowish-brown, thoracal apodemes and sutures, as well as the shoulder spots light brown. Legs pale ochreous. Length of fore wing 1.4-2.0 mm, of hind wing1.1-1.4 $\mathrm{mm}$. Wing membrane light yellowish-brown. Pregenital part of abdomen pale ochreous.

Male terminalia (Figs 47-51) well sclerotized, medium brown. Hypandrium in lateral view about as high as long. Processus terminalis well developed, with in lateral view acute, in ventral view rounded caudal endings, and with broad and rather deep, u-shaped median incision. A well developed inner structure is connected to the dorsal surface of hypandrium. Its anterior part rounded dorsally, posterior one pointed caudally in lateral view. Processus lateralis large, subtriangular, directed caudally. Anterior apodeme of hy-
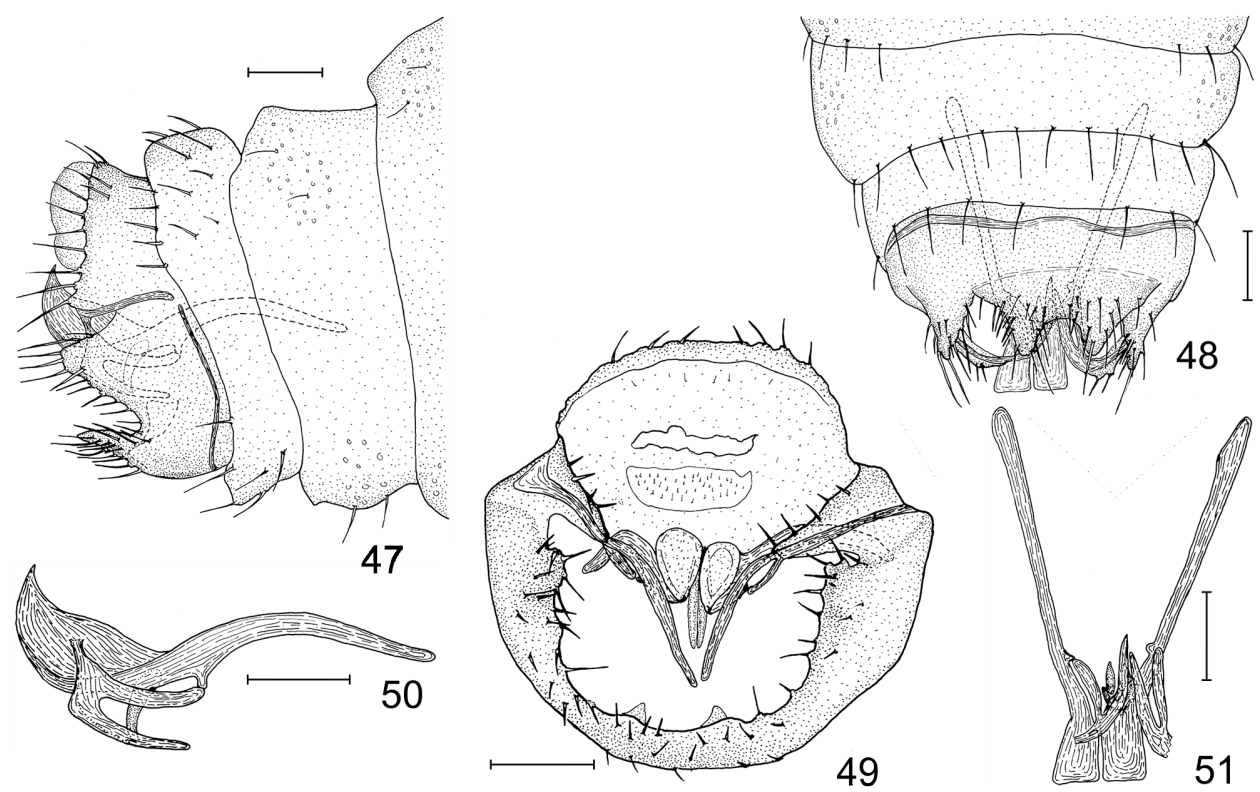

Figs 47-51. Coniopteryx (C.) ihorombeana sp. n.: $47=$ male terminalia, lateral view, $48=$ male terminalia, ventral view, $49=$ male terminalia, caudal view, $50=$ male internal genitalia, lateral view, $51=$ male internal genitalia, ventral view. Scales: $0.04 \mathrm{~mm}$ 
pandrium very narrow, its median part in some cases almost absent. Ventral apodeme of gonarcus evenly thin. Stylus forked; its inner branch rather narrow, in lateral view slightly bent, simple. No detectable ventral bridge between the two inner branches. Outer branch of the stylus slender, pointed (especially in ventral view), and directed forwards. Proximal part of paramere distinctly bent down, while the processus apicalis of this sclerite very broad and slightly hooked in lateral view. Processus ventralis normally developed. Penis sclerite consists of two, in lateral view slightly bent and ventrally pointed rods. Besides, the territory around the anus (including the tenth sternite) unusually protruded in all examined specimens.

Remarks: Because of the structure of male genitalia (e.g.: the non-truncated processus apicalis of paramere) and absence of modifications on the head Coniopteryx (C.) ihorombeana sp. n. belongs to the Coniopteryx exigua group sensu SzIRÁki (2005), however, because of the very wide processus apicalis, its position somewhat transitorial towards the Coniopteryx tineiformis group. Regarding the curving up ending and distinct, but not large processus ventralis of paramere, the well developed processus terminalis of hypandrium with ushaped median incision, the subtriangular processus lateralis Coniopteryx ihorombeana sp. n. slightly resembles to the Coniopteryx exigua Withycombe, 1925. The main distinctive features of the new species are:

- $\quad$ the presence of setae on flagellar segments;

- $\quad$ the rounded endings of processus terminalis of hypandrium;

- $\quad$ the broad and rather deep median incision of hypandrium;

- $\quad$ the distinctly bent down proximal part of paramere;

- $\quad$ the forwards directing outer branch of the stylus;

- $\quad$ the paired structure of penis.

Etymology: The new species was named after the Ihorombe Region, where a large part of the type material was collected.

\section{Coniopteryx (Coniopteryx) microcauda sp. n.}

$$
\text { (Figs 52-57) }
$$

Examined material - Holotype: male, Madagascar, Antsiranana Province, Montagne d'Ambre National Park, 12³1' S, 4911' E, 975 m a.s.l., 11. II - 4. III. 2001, Malaise trap, leg.: I, ES, HH; deposited in the collection of CAS; CASTYPE number: 20019. Paratypes: 1 male, Antsiranana Province, Sakalava Beach, $12^{\circ} 15^{\prime} 46^{\prime \prime}$ S, 49 $23^{\prime} 51^{\prime \prime}$ E, $10 \mathrm{~m}$ a.s.l., 27. IV - 13. V. 2001-25 dwarf littoral forest, Malaise trap, leg.: HH; 1 male, Toamasina Province, botanic

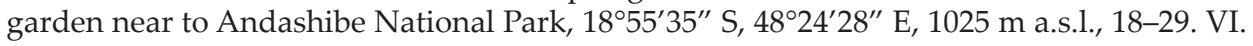
2001, tropical rain forest, Malaise trap, leg.: HH;. One of the paratypes is deposited in the collection of CAS, while the other in HNHM.

Description: Length of the body 1.3-1.4 mm. Head capsule and palpi light brown or pale ochreous. Anterior edge of vertex with a prominent, laterally flattened projection 
between the antennae. Eyes relatively small, black. Antennae (Fig. 52) light brown, $0.8 \mathrm{~mm}$, 25-28 segmented. Scape about as wide as long, pedicel somewhat longer than wide. In the basal half of the antennae the flagellar segments 1.6-1.8 times, in apical half cca. 1.5 times wider than long. Pedicel has an almost invisible setose outgrowth, while the first flagellar segment has a highly elongated, prominent one, with a few setae. Inner regular seta of the first flagellar segment well separated from the outgrowth, and has a considerable base. Ordinary hairs are distributed partly irregularly, partly in an apical ring on the scape, in two regular rings on pedicel, and rather irregularly on the flagellar segments. Scale-like hairs dispersed on considerable part of pedicel, and arranged in a rather weak apical whorl on the flagellomeres.

Thorax and legs light brown, or pale ochreous, thoracal apodemes and sutures medium, or light brown, shoulder spots medium brown. Length of the fore wing 1.5-1.7 mm, of hind wing 1.2-1.3 mm. Wing membrane and veins light yellowish-brown. Pregenital part of the abdomen pale ochreous.

Male terminalia (Figs 53-57) well sclerotized, medium brown. Hypandrium in lateral view distinctly higher than long. Processus terminalis short and narrow, with rounded caudal endings bent slightly laterally. Median incision of processus terminalis u-shaped. A pair of moderately high, crest-like hyaline inner structure is attached dorsally to the processus terminalis of hypandrium. Processus lateralis long, tapering and directed caudally. Its setae moderately long, without prominent bases. Anterior apodeme of hypandrium
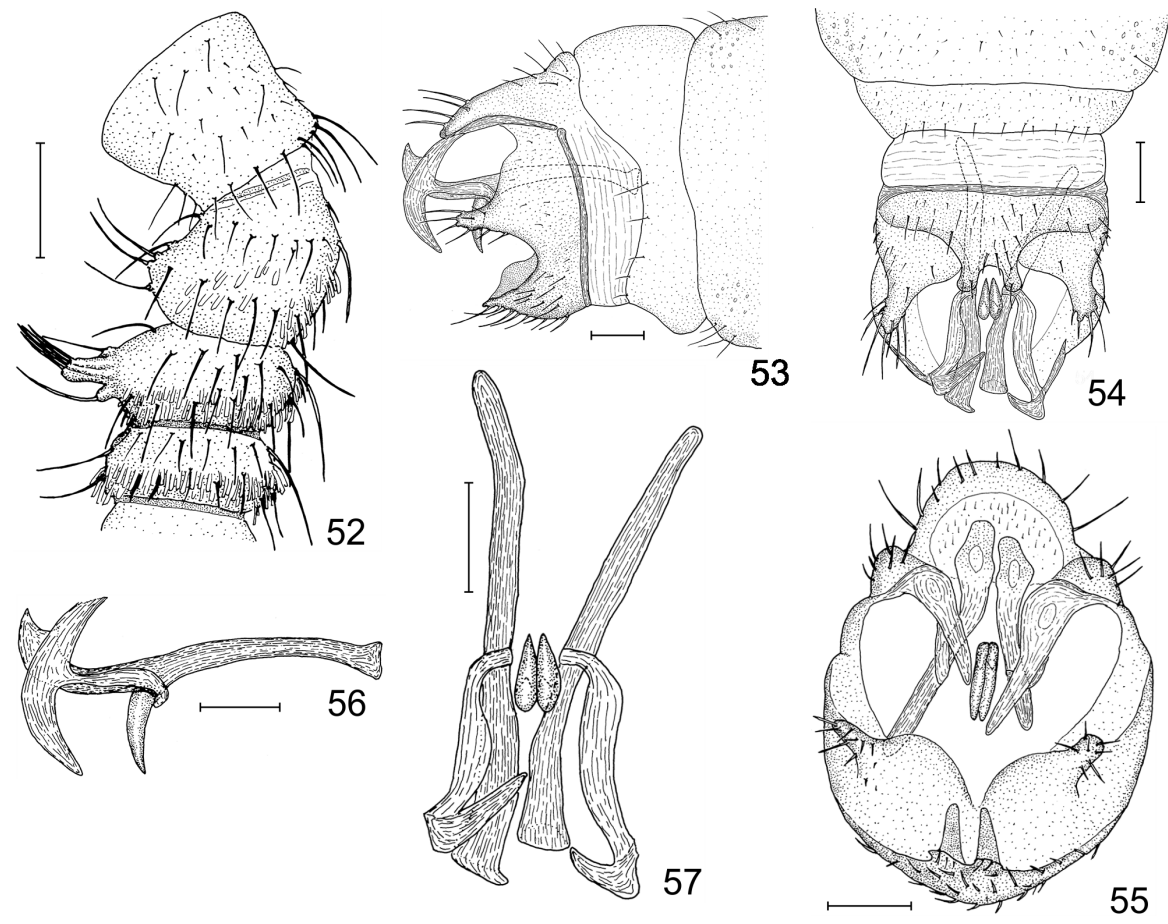

Figs 52-57. Coniopteryx (C.) microcauda sp. n.: $52=$ basal part of antenna, $53=$ male terminalia, lateral view, $54=$ male terminalia, ventral view, $55=$ male terminalia, caudal view , $56=$ male internal genitalia, lateral view, $57=$ male internal genitalia, ventral view. Scales: $0.04 \mathrm{~mm}$ 
evenly narrow. The lateral and ventral part of the ninth segment being before the anterior apodeme is rather broad and more sclerotized and darkened as in many other species of the genus. Ventral apodeme of gonarcus rather narrow, but widened caudally. Stylus forked; its outer branch broad and directed ventrally. Inner branch without special modifications, and it is moderately broad. No distinct ventral bridge between the inner branches of styli. Anterior part of paramere slightly bent and truncated in lateral view, while the pipe-like posterior part of this sclerite evenly widening caudally. Processus apicalis of paramere simple, and slightly bifid in lateral view. Processus ventralis small but detectable. The relatively large double penis sclerite flattened laterally and pointed distally.

Remarks: Coniopteryx (C.) microcauda sp. n. belongs to the Coniopteryx lobifrons group sensu SzIráki (2005), and because of the paired inner structure of hypandrium, the relatively small processus lateralis, the narrow anterior apodeme of hypandrium and the ventrally directed outer branch of the stylus it is related most closely to Coniopteryx (C.) geniculata sp. n.

The main distinctive features of Coniopteryx (C.) microcauda sp. n. are:

- $\quad$ the indistinct inner outgrowth of pedicel;

- $\quad$ the rounded caudal endings of the narrow processus terminalis;

- u-shaped median incision of processus terminalis;

- $\quad$ relatively low dorsal inner structure of hypandrium;

- $\quad$ absence of serration on the outer branch of stylus;

- $\quad$ simple structure of the inner branch of stylus, without distinct bridge below the parameres;

- $\quad$ the different shape of the paramere.

Etymology: The new species is named after the small, but distinct processus terminalis of hypandrium.

\section{Coniopteryx (Coniopteryx) pseudoceylonica sp. n.}

$$
\text { (Figs 58-62) }
$$

Examined material - Holotype: male, Madagascar, Fianarantsoa Province, Ranomafana National Park, Vahiporara at broken bridge, $21^{\circ} 13^{\prime} 34^{\prime \prime}$ S, $47^{\circ} 22^{\prime} 11^{\prime \prime}$ E, $1100 \mathrm{~m}$ a.s.1., 2128. II. 2002, mountain rain forest, Malaise trap, leg.: HH; deposited in the collection of CAS; CASTYPE number: 20020. Paratypes: 1 male, Madagascar, Fianarantsoa Province, Ranomafana National Park, Belle Vue at Talatakely, $21^{\circ} 15^{\prime} 59^{\prime \prime}$ S, $47^{\circ} 25^{\prime} 13^{\prime \prime}$ E, $1200 \mathrm{~m}$ a.s.l., 8-15. XI. 2001, secondary tropical forest, Malaise trap, leg.: HH; 1 male, same data but 28. IV - 5. V. 2002; 1 male, same data but 15-27. IV. 2003; 1 male, Madagascar, Fianarantsoa Province, Ranomafana National Park, radio tower at forest edge, $21^{\circ} 15^{\prime} 03^{\prime \prime}$ S, $47^{\circ} 24^{\prime} 26^{\prime \prime}$ E, $1130 \mathrm{~m}$ a.s.1., 15-27. IV. 2003, mixed tropical forest, Malaise trap, leg.: HH. One of the paratypes housed in HNHM, the others in the collection of CAS.

Description: Length of the body 1.6-1.8 mm. Head capsule and palpi light brown or pale ochreous. Frons connected to vertex in a right angle. Eyes relatively small, black. Antennae light brown, 0.9-1.1 mm, 25-26 segmented. Scape 1.3-1.6 times, pedicel 1.3-1.7 
times longer than wide. Flagellar segments in the basal half of antennae 1.4-1.5 times wider than long, while in the apical half about as wide as long. Ordinary hairs irregularly cover the scape and pedicel, and situated in two rather irregular rigs on flagellar segments. Setae moderately long. Scale-like hairs are on large part of pedicel, and in a broad but moderately dense whorl on flagellar segments.

Thorax pale ochreous, thoracal apodemes and sutures medium or dark brown, shoulder spots medium brown. Setae on fore femora prominent basally, but lessening distally. Length of the fore wing 1.5-1.9 mm, of hind wing 1.1-1.5 mm. Membrane of wings yellowish brown, colour of veins light brownish yellow. Pregenital part of abdomen pale ochreous.

Male terminalia (Figs 58-62) well sclerotized, medium brown. Hypandrium in lateral view about as high as long. Processus terminalis directed dorsally above a caudal rim, and in a right angle to the finely grooved ventral part of hypandrium. Median incision of processus terminalis moderately deep, with an u-shaped lower and diverged upper part. (It is worth to mention that - because of it position - processus terminalis resembles to the inner structure of hypandrium in some other Coniopteryx species, however it does not homologous with that structure.) Processus lateralis moderately long, blunt and directed caudally. Anterior apodeme of hypandrium broad laterally, with an acute side branch, narrow and bent backwards ventrally. Apodeme of gonarcus anteriorly incomplete, and situated largely in the middle line of this sclerite. Part of gonarcus being ventrally of the apodeme sclerotized more intensively than it is usual. Stylus forked, and in lateral view broad. No detectable ventral bridge between the two inner branches of stylus. Proximal part of paramere rather thin, and tapering anteriorly in lateral view. Processus apicalis
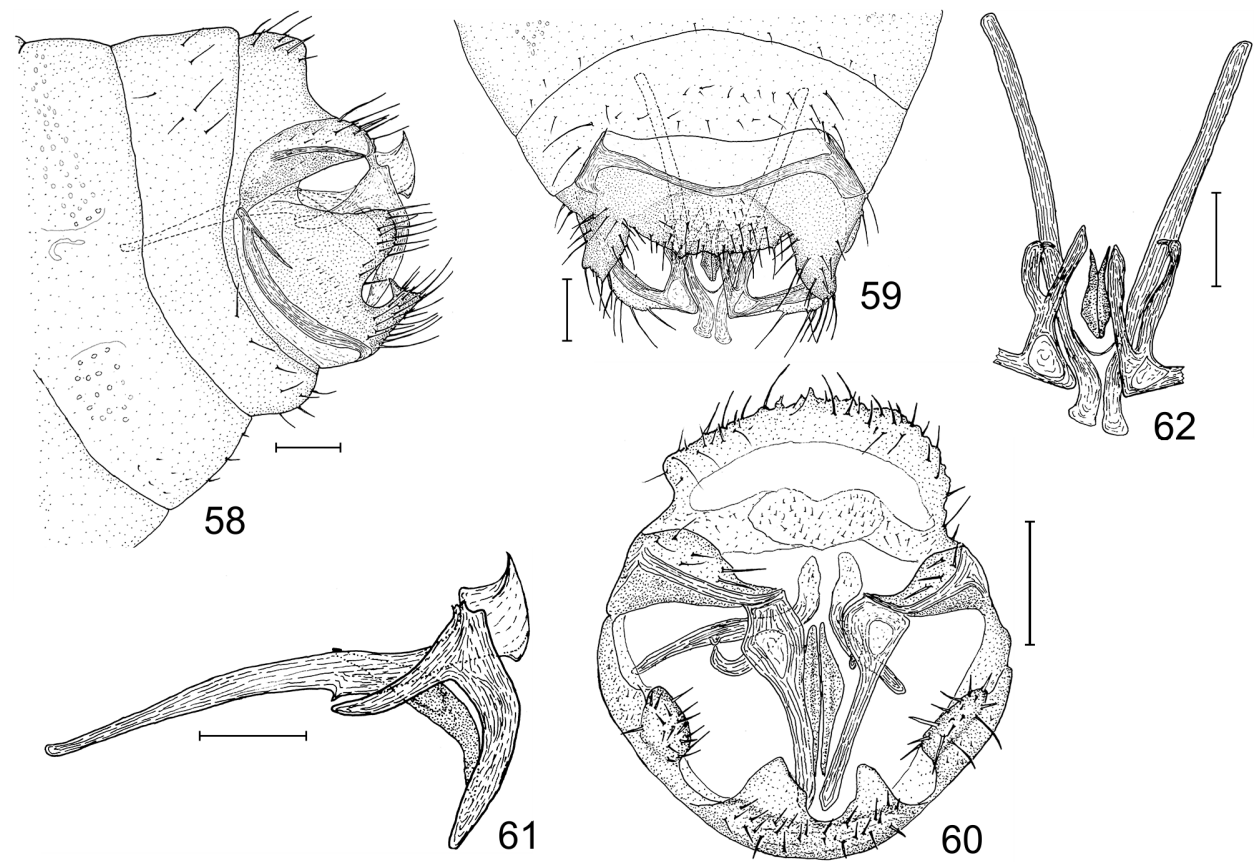

61

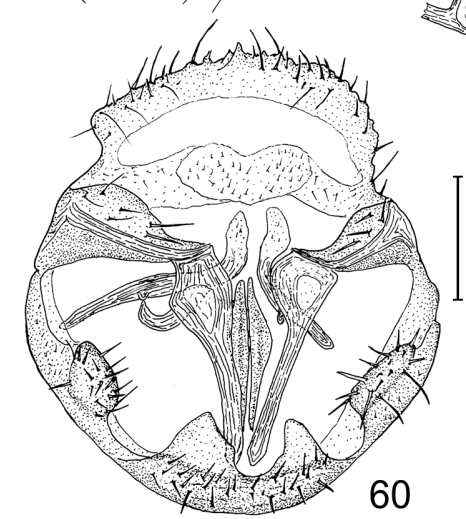

Figs 58-62. Coniopteryx (C.) pseudoceylonica sp. n.: $58=$ male terminalia, lateral view, $59=$ male terminalia, ventral view , $60=$ male terminalia, caudal view , $61=$ male internal genitalia, lateral view, $62=$ male internal genitalia, ventral view. Scales: $0.04 \mathrm{~mm}$ 
weakly sclerotized, slender in caudal view, with a prominent, sharp ventral jut in lateral view. Processus ventralis of paramere small but distinct. Penis sclerite consists of two unusually well sclerotized, large, in their middle part rather broad blades. Caudally of penis there is a thin, slightly sclerotized structure, visible in ventral view.

Remarks: Coniopteryx (C.) pseudoceylonica sp. n. belongs to the Coniopteryx tineiformis group sensu SzIRÁKI (2005). Because of the similarity regarding the shape of the median incision of processus terminalis, the broad stylus in lateral view, the similar building up of paramere and especially the similar position of the apodeme of ectoproct Coniopteryx ceylonica Meinander, 1982 may be regarded as its closest relative.

The main distinctive features of the new species are:

- $\quad$ the dorsally directed processus terminalis above a caudal rim;

- $\quad$ the bent backwards anterior apodeme of hypandrium;

- $\quad$ absence of a ventral bridge between the inner branches of stylus;

- $\quad$ in caudal view slender processus apicalis of paramere;

- the unusually well sclerotized and relatively large penis sclerite;

- $\quad$ presence of prominent setae on the basal part of first femora.

Etymology: The new species is named after the similarity to the Coniopteryx ceylonica from Sri Lanka.

\section{Coniopteryx (Coniopteryx) pseudomalgasensis sp. n.} (Figs 63-68)

Examined material - Holotype: male, Madagascar, Fianarantsoa Province, Ranomafana National Park, Belle Vue at Talatakely, $21^{\circ} 15^{\prime} 59^{\prime \prime}$ S, $47^{\circ} 25^{\prime} 13^{\prime \prime}$ E, 1200 m a.s.1., 15-22. XI. 2001, secondary tropical forest, Malaise trap, leg.: HH; deposited in the collection of CAS; CASTYPE number: 20021. Paratypes: 1 male, same data as holotype, but $16 . \mathrm{X}-8$. XI. 2001; 5 males, Madagascar, Antananarivo Province, $3 \mathrm{~km}$ NE of Andranomay, $18^{\circ} 28^{\prime} 24^{\prime \prime}$ S, 47 57'36" E, 1300 m. a.s.l., mountain rainforest, 5-13. XII. 2000, Malaise trap, leg.: F, G et al.; 1 male, Madagascar, Fianarantsoa Province, Ranomafana National Park, Vahiporara at broken bridge, $21^{\circ} 13^{\prime} 34^{\prime \prime}$ S, $47^{\circ} 22^{\prime} 11^{\prime \prime}$, $1100 \mathrm{~m}$ a.s.l., 22-28. XI. 2001, mountain rain forest, Malaise trap, leg.: HH. One of the paratypes is deposited in HNHM, while the others in the collection of CAS.

Description: Length of the body $1.5-1.8 \mathrm{~mm}$. Head capsule largely pale ochreous, but posterior part of genae light brown. Anterior edge of vertex with a prominent, laterally flattened projection between the antennae. Eyes moderately large, black. Antennae (Fig. 63) light or medium brown, relatively long: $1.0-1.3 \mathrm{~mm}, 27-31$ segmented. Scape as wide as, or slightly wider than long, pedicel 1.1-1.3 times longer than wide. The flagellar segments in the basal half of the antennae 2.0-2.6 times, in the apical half 1.4-1.9 times wider than long. Pedicel with a small group of setae, but without a detectable inner outgrowth, while the inner setose outgrowth of the first flagellar segment prominent. Regular inner seta of this segment separated distinctly from the outgrowth. Ordinary hairs are in an api- 
cal ring on the scape, and in two very irregular rings on pedicel and flagellar segments. Scale-like hairs dispersed on considerable part of pedicel, and the flagellomeres also are almost entirely covered by this type of hairs. Palpi are light brown.

Thorax and pregenital part of abdomen pale ochreous. Thoracal apodemes, sutures and the shoulder spots medium or dark brown. Legs, wing membrane and longitudinal veins light brown. Length of the fore wing 1.8-2.2 $\mathrm{mm}$, of hind wing 1.4-1.8 mm.

Male terminalia (Figs 64-68) well sclerotized, dark or medium brown. Hypandrium in lateral view about as high as long. Processus terminalis well developed, with broad and deep, u-shaped median incision. Processus lateralis long, and directed caudally. Its setae moderately long, without prominent bases. Anterior apodeme of hypandrium evenly broad and nearly straight in ventral view. Ventral apodeme of gonarcus strong and broad. Stylus forked; its outer branch pointed, in lateral view wide and curved forwards. Inner branch moderately broad and without special modifications. No ventral bridge between the inner branches of styli. Paramere sinuated in lateral view, and its anterior ending curved outwards. Processus apicalis of paramere in lateral view pointed with a rounded preapical lobe, while in caudal view it looks like as a moderately wide bent strip. Microtrichiae of processus apicalis distinctly visible. Processus ventralis not large, but prominent. Penis sclerite consists of a pair of thin, but rather long rods.
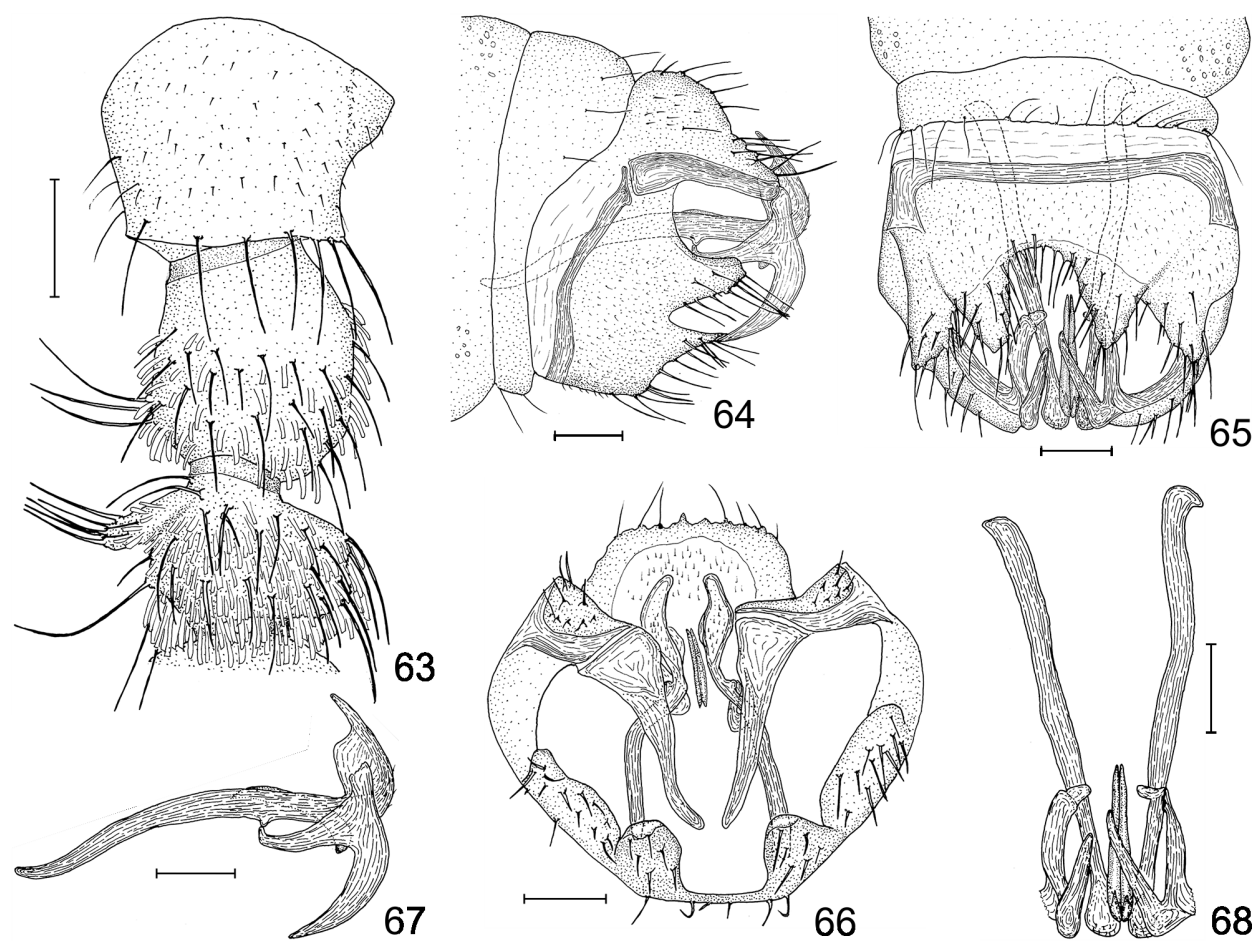

Figs 63-68. Coniopteryx (C.) pseudomalgasensis sp. n.: $63=$ basal part of antenna, $64=$ male terminalia, lateral view, $65=$ male terminalia, ventral view, $66=$ male terminalia, caudal view, $67=$ male internal genitalia, lateral view, $68=$ male internal genitalia, ventral view. Scales: $0.04 \mathrm{~mm}$ 
Remarks: Coniopteryx (C.) pseudomalgasensis sp. n. belongs to the Coniopteryx lobifrons group sensu SzIRÁKI (2005), and because of the similarities in the structure of hypandrium it is related most closely to Coniopteryx (C.) malgasensis Sziráki, 2015.

The main distinctive features of the new species are:

- $\quad$ absence of a distinct inner outgrowth of the pedicel;

- in ventral view almost straight anterior apodeme of hypandrium;

- $\quad$ the more deep median incision of processus terminalis;

- $\quad$ absence of prominent bases of the setae on processus lateralis;

- the broad ventral apodeme of gonarcus;

- $\quad$ the moderately broad inner branch of the stylus;

- $\quad$ absence of a ventral bridge between the inner branches of stylus.

Etymology: The new species named after the obvious similarity to the earlier described coniopterygid species Coniopteryx malgasensis.

Coniopteryx (Coniopteryx) ranomafanana sp. n. (Figs 69-74)

Examined material - Holotype: male, Madagascar, Fianarantsoa Province, Ranomafana National Park, radio tower at forest edge, $21^{\circ} 15^{\prime} 03^{\prime \prime}$ S, $47^{\circ} 24^{\prime} 26^{\prime \prime}$ E, $1130 \mathrm{~m}$ a.s.l., 10-14. I. 2002, mixed tropical forest, Malaise trap, leg.: HH; deposited in the collection of CAS CASTYPE number: 20022. Paratypes: 3 males, same data as holotype, but 8-15. X. 2001. Two of the paratypes housed in the collection of CAS, one deposited in HNHM.

Description: Length of the body 1.6-1.8 mm. Head capsule pale ochreous or light brown, but genae somewhat darker than the other parts of the head. Anterior edge of vertex with a laterally flattened projection between the antennae. Palpi pale ochreous. Antennae (Fig. 69) medium or dark brown, 1.2-1.3 mm, 29-31 segmented. Scape slightly wider than long, pedicel 1.2-1.5 times longer than wide. The flagellar segments in the basal half of antennae 1.8-2.4 times, in the apical half 1.2-1.9 times wider than long. Pedicel without setose inner outgrowth, however has two rather short, basally curved setae. Inner outgrowth of first flagellar segment moderately prominent, but distinct and broad, with relatively short and straight setae. This outgrowth is well separated from the regular inner seta of the first flagellar segmenet. The regular inner setae of the 1-4 flagellar segments have well developed bases. Ordinary hairs situated mostly in an apical ring on the scape, in two very irregular rings on pedicel, while in a regular apical, and in an irregular subapical ring on flagellar segments. Scale-like hairs are dispersed sparsely on pedicel, and in a rather thin apical whorl on the flagellomeres.

Thorax light brown, thoracal sutures and apodemes medium or dark brown, shoulder spots dark brown. Legs, wing membrane and veins light brown. Length of the fore wing 1.9-2.2 mm, of hind wing 1.5-1.8 mm. Pregenital part of abdomen pale ochreous.

Male terminalia (Figs 70-74) well sclerotized, medium brown, with dark brown apodemes. Hypandrium in lateral view distinctly higher than long. Ventro-caudal line of this 
sclerite turning up abruptly. The very short basal (anterior) part of processus terminalis directed upwards, while the distal endings turn dorso-caudally. These in lateral view are acute, in ventral view blunt lobe-like. Median incision broad, u-shaped in caudal view. Processus lateralis triangular, directed caudally, with rather long setae. Anterior apodeme of hypandrium evenly narrow. Ventral apodeme of gonarcus proximally wide, distally narrow. Setae of gonarcus situated on strong bases. Stylus forked; its inner branch gradually tapering in lateral, evenly broad band-like in ventral view. There is a slightly sclerotized ventral bridge between the two inner branches. Outer branch of stylus slightly bent forward having a finely lacerated caudal edge and 2-3 teeth on its tip. Anterior part of paramere in lateral vew straight. Processus apicalis dorsally pointed, with well developed, acute preapical lobe in lateral view, and with a small ventral crest, detectable in caudal or ventral view. Apart from this crest, the processus apicalis seems to be a simple oval structure in caudal view. Processus ventralis of paramere small, but distinct. Penis consists of two thin rods pointed in lateral view, and covered caudally by some weakly sclerotized structure, visible in ventral view.
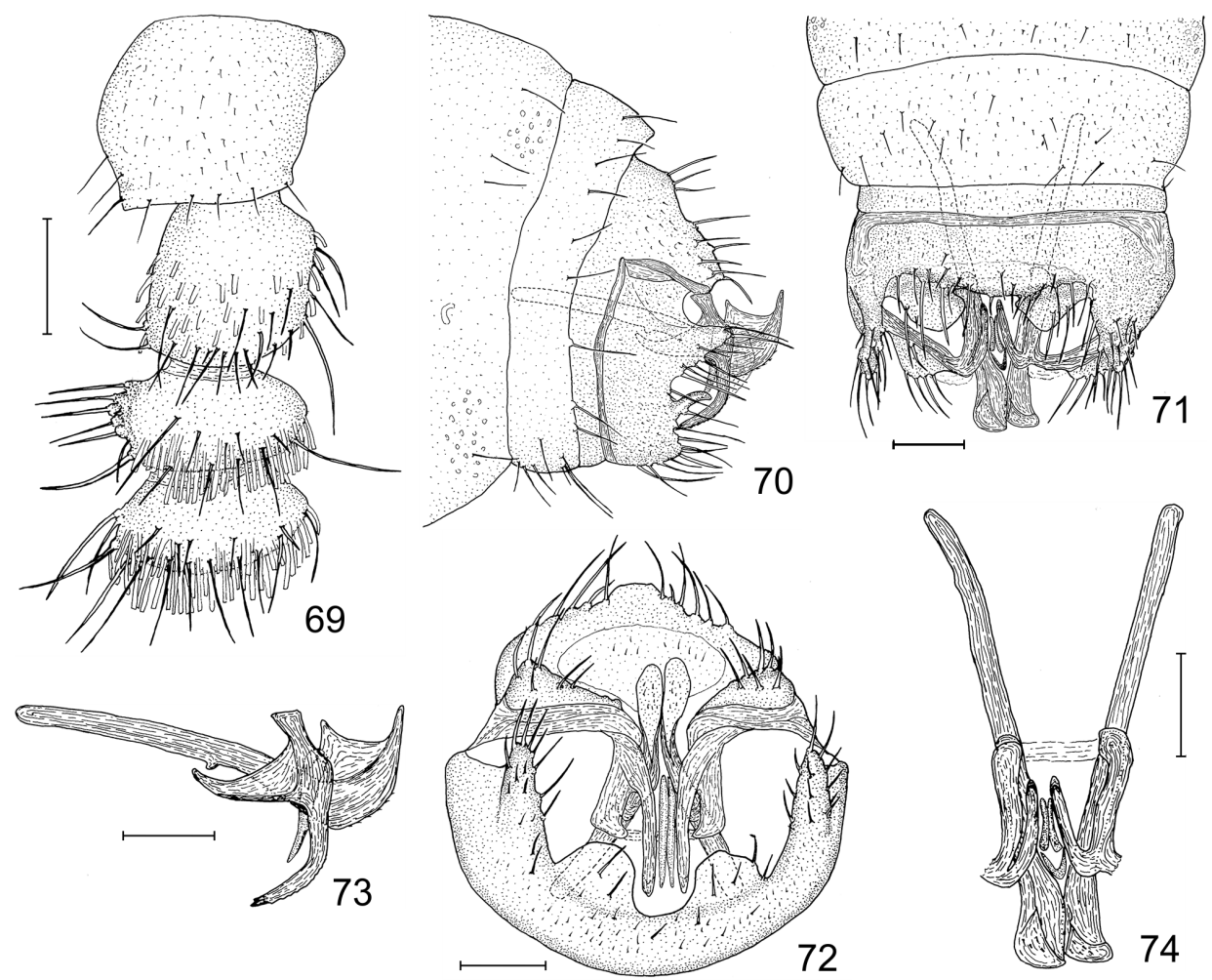

Figs 69-74. Coniopteryx (C.) ranomafanana sp. n.: $69=$ basal part of antenna, $70=$ male terminalia, lateral view, $71=$ male terminalia, ventral view, $72=$ male terminalia, caudal view, $73=$ male internal genitalia, lateral view, $74=$ male internal genitalia, ventral view. Scales: $0.04 \mathrm{~mm}$ 
Remarks: Coniopteryx (C.) ranomafanana sp. $\mathrm{n}$. belongs to the Coniopteryx lobifrons group sensu SzIRÁKI (2005). Because of the evenly narrow anterior apodeme of hypandrium, the very similar structure of the outer branch of the stylus and presence of well developed bases of usual inner seta on several flagellar segments in the basal half of the antennae it should be closely related to Coniopteryx (C.) fianarantsoana sp.n.

The main distinctive features of Coniopteryx (C.) ranomafanana sp. $\mathrm{n}$. are:

- $\quad$ the distinct and broad inner outgrowth of first flagellar segment;

- the special line of hypandrium in lateral view, in connection of the presence of caudally directed, lobe-like endings of processus terminalis situated on both sides of the broad, u-shaped median incision;

- $\quad$ the anteriorly broadened ventral apodeme of gonarcus;

- absence of an inner structure of hypandrium;

- in ventral view evenly broad, band-like inner branch of stylus;

- $\quad$ presence of a well developed, in lateral view acute preapical lobe of processus apicalis of paramere.

Etymology: The new species is named after the Ranomafana National Park, where the type material was collected.

\section{Coniopteryx (Coniopteryx) schizostylaris sp. n.} (Figs 75-80)

Examined material - Holotype: male, Madagascar, Fianarantsoa Province, Ranomafana National Park, Vahiporara at broken bridge, $21^{\circ} 13^{\prime} 34^{\prime \prime}$ S, $47^{\circ} 22^{\prime} 11^{\prime \prime}$ E, $1100 \mathrm{~m}$ a.s.l., 28. XI - 6. XII. 2001, mountain rain forest, Malaise trap, leg.: HH; deposited in the collection of CAS; CASTYPE number: 20023. Paratypes: 1 male, same data as holotype, but 26. VI - 5 . VII. 2002; 1 male, Madagascar, Antsiranana Province, Ampasindava, Forèt d'Ambilanivy,

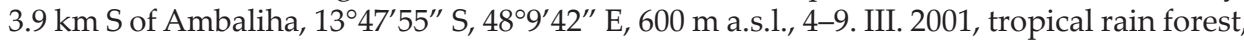
Malaise trap, leg.: F, G et al.; 1 male, Madagascar, Antsiranana Province, Sakalava Beach, 12 $15^{\prime} 46^{\prime \prime}$ S, 49 $23^{\prime} 51^{\prime \prime}$ E, 10 m a.s.l., 15. II - 6. III. 2001, dwarf littoral forest, Malaise trap, leg.: HH; 1 male, Madagascar, Fianarantsoa Province, Ranomafana National Park, Belle Vue at Talatakely, $21^{\circ} 15^{\prime} 59^{\prime \prime}$ S, $47^{\circ} 25^{\prime} 13^{\prime \prime}$ E, $1200 \mathrm{~m}$ a.s.l., 15-22. XI. 2001, secondary tropical forest, Malaise trap, leg.: HH; 1 male, same data but13-23. VI. 2002; 1 male, Madagascar, Toamasina Province, botanic garden near to entrance to Andasibe National Park, $18^{\circ} 55^{\prime} 35^{\prime \prime}$ S, 48²4'28”' E, $1025 \mathrm{~m}$ a.s.l., 5-19. IX. 2001, tropical forest, Malaise trap, leg.: HH. One of the paratypes deposited in HNHM, while the others in the collection of CAS.

Description: Length of the body 1.2-1.5 mm. Head capsule light yellowish brown. Anterior edge of vertex with a laterally flattened projection between the antennae. Eyes very large, black. Antennae (Fig. 75) light yellowish brown, 0.9-1.2 mm, 26-28 (mostly 28) segmented. Scape as wide as long, pedicel 1.1-1.3 times longer than wide. The flagellar segments in the basal half of the antennae 2-3 times, in the apical half 1.4-1.7 times wider than long. Pedicel and first flagellar segment without distinct setose inner outgrowth, but 
both these segments have an inner group of setae. The regular inner seta of the first flagellar segment separated distinctly from the mentioned setose spot of this segment. Ordinary hairs situated in an apical ring on the scape, in two rings on pedicel, and rather irregularly on the flagellar segments. Some scale-like hairs are dispersed sparsely on pedicel, while this type of hairs are arranged in a moderately dense whorl on the apical half of the flagellomeres. Palpi light yellowish brown.

Thorax light brown, thoracal sutures and apodemes medium or dark brown, shoulder spots light or medium brown. Legs, wing membrane and longitudinal veins light yellowish brown. Length of the fore wing 1.6-2.0 mm, of hind wing 1.2-1.5 mm. Pregenital part of abdomen pale ochreous.

Male terminalia (Figs 76-80) well sclerotized, medium brown, with dark brown apodemes. Hypandrium in lateral view about as high as long. Processus terminalis well developed, with a hyaline dorsal inner structure. Median incision deep and - disregarding the median part of the inner structure - forming an elongated u-shape. Processus lateralis long and directed caudally. Its setae are moderately long, with prominent bases. Anterior apodeme of hypandrium evenly narrow. Ventral apodeme of gonarcus rather narrow also, but its anterior part broadened. Stylus forked; its inner branch moderately broad without
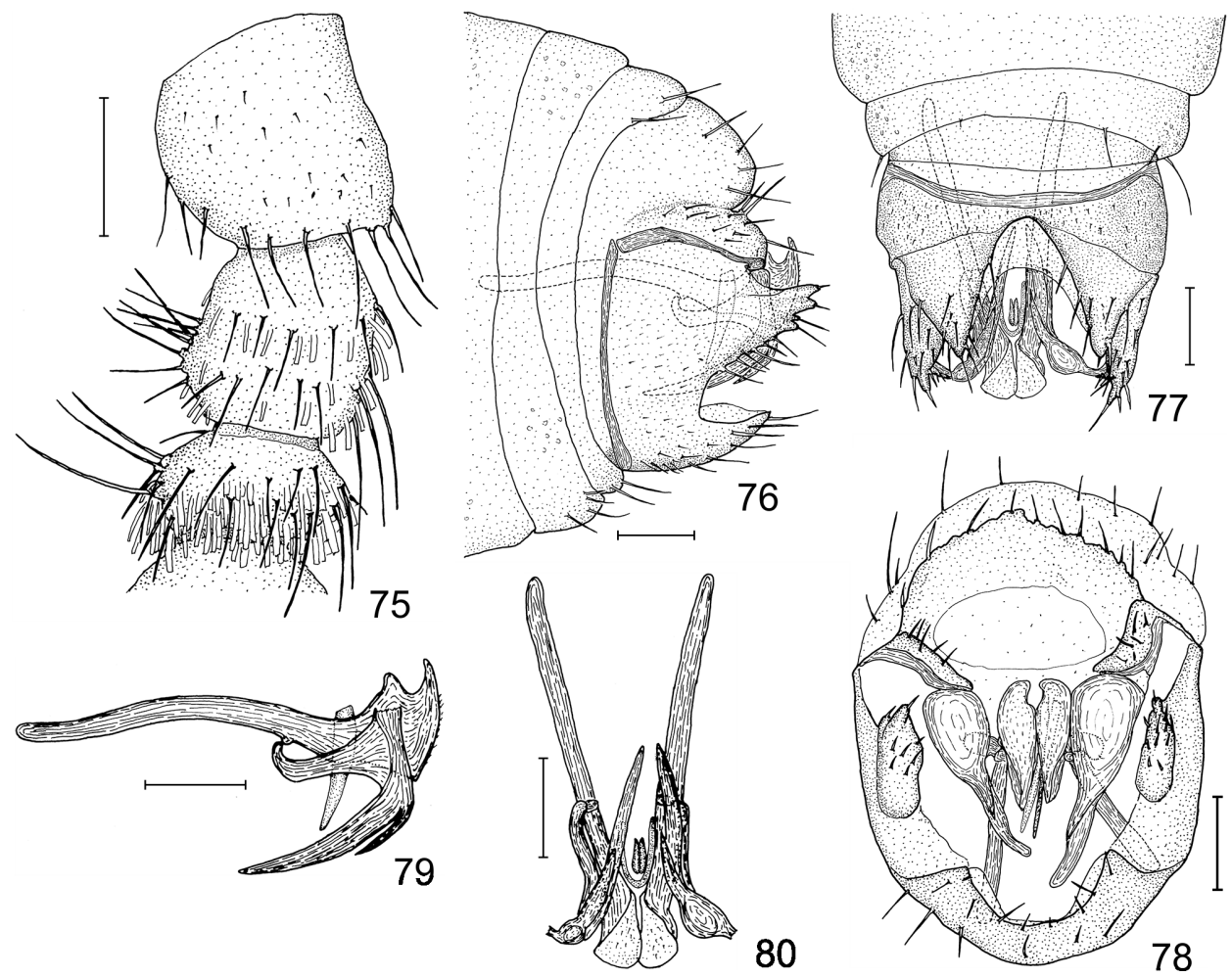

Figs 75-80. Coniopteryx (C.) schizostylaris sp. n., male: $75=$ basal part of antenna, $76=$ male terminalia, lateral view, $77=$ male terminalia, ventral view, $78=$ male terminalia, caudal view, $79=$ male internal genitalia, lateral view, $80=$ male internal genitalia, ventral view.

Scales: $0.04 \mathrm{~mm}$ 
special modifications, and no ventral bridge between the two inner branches. Outer branch of stylus long, pointed, curved forwards and sharply bifid; i.e.: it has a long tooth which runs parallel with the main part of this branch. Paramere in lateral view slightly bent. Its processus apicalis seems to be pointed in lateral view, with a blunt preapical lobe dorsally, besides, it has a crest ventrally. In caudal view the processus apicalis rather narrow, and curved inwards dorsally. Processus ventralis small. Penis consists of two thin blades covered caudally and laterally with some weakly sclerotized structure, visible in ventral view.

Remarks: Coniopteryx (C.) schizostylaris sp. $\mathrm{n}$. belongs to the Coniopteryx lobifrons group sensu SzIRÁKI (2005). Because of the special structure of stylus and the atrophied outgrowth of first flagellar segment the new species has a rather separate position within this group, however, the long and directed caudally processus lateralis, the well developed processus terminalis and the $\mathrm{u}$-shaped median incision indicate that Coniopteryx (C.) pseudomalgasensis $\mathrm{sp}$. n. may be regarded as its closest relative.

The main distinctive features of Coniopteryx (C.) schizostylaris sp. n. are:

- absence of a distinct inner outgrowth of the first flagellar segment;

- presence of a hyaline inner structure of hypandrium;

- prominent bases of the setae on processus lateralis;

- narrow ventral apodeme of gonarcus;

- $\quad$ long and sharply bifid outer branch of stylus.

Etymology: The new species named after the surprising bifid structure of the outer branch of stylus.

\section{Coniopteryx (Coniopteryx) spinicauda sp. n.}

(Figs 81-86)

Examined material - Holotype: male, Madagascar, Antsiranana Province, Montagne d'Ambre National Park, 12 $30^{\prime} 52^{\prime \prime}$ S, $49^{\circ} 10^{\prime} 53^{\prime \prime}$ E, 960 m a.s.l., 19. III - 5. IV. 2001, Malaise trap, leg.: I, ES \& HH; deposited in the collection of CAS; CASTYPE number: 20024. Paratypes: 2 males, same data as holotype; 1 male, Madagascar, Antsiranana Province, $7 \mathrm{~km} \mathrm{~N}$ of Joffreville, $12^{\circ} 20^{\prime}$ S, $49^{\circ} 15^{\prime}$ E, 360 m a.s.1., 6-20. III. 2001, dry forest, Malaise trap, leg.: HH; 1 male, Madagascar, Antsiranana Province, Montagne d'Ambre National Park, $12^{\circ} 30^{\prime} 52^{\prime \prime}$ S, 49¹0'53" E, 960 m a.s.l., Malaise trap, leg.: I, ES \& HH; 1 male, Madagascar, Toamasina Province, $7 \mathrm{~km}$ SE of Andasibe National Park headquarters, $18^{\circ} 57^{\prime} 46^{\prime \prime} \mathrm{S}, 48^{\circ} 27^{\prime} 10^{\prime \prime} \mathrm{E}$, 1050 m a.s.l., 9-23. IV. 2001, tropical forest, Malaise trap, leg.: HH; 1 male, Madagascar, Toamasina Province, botanic garden near to entrance to Andasibe National Park, $18^{\circ} 55^{\prime} 35^{\prime \prime}$ S, $48^{\circ} 24^{\prime} 28^{\prime \prime}$ E, $1025 \mathrm{~m}$ a.s.1., 8-14. X. 2001, tropical forest, Malaise trap, leg.: I \& HH. One of the paratypes deposited in HNHM, while the others in the collection of CAS.

Description: Length of the body 1.4-1.8 mm. Head capsule and palpi light brown. Anterior edge of vertex with a prominent, laterally flattened projection between the antennae. Eyes moderately large, black. Antennae (Fig. 81) 0.9-1.1 mm, 27-28 segmented, dark 
brown, with exception of medium or light brown scape, which about as long as wide. Pedicel slightly longer than wide, basal antennal segments 2 times, median ones about 1.5 times as wide as long. Pedicel with a rather indistinct, the first flagellar segment with a moderately large apical projection. Setae of these projections moderately long. Ordinary hairs are arranged in two regular rings on pedicel and on flagellar segments as well. Scalelike hairs situated mostly in two thin whorls on pedicel and in a dense apical whorl on flagellar segments. Besides, there are also some spots of this type of hairs on other parts of the first flagellar segment.

Thorax pale ochreous, its sutures and apodemes medium or light brown, shoulder spots dark brown. Wing membrane light or medium brown. Length of the fore wing 1.7$1.8 \mathrm{~mm}$, of hind wing 1.3-1.6 mm. Pregenital part of abdomen pale ochreous.

Male terminalia (Figs 82-86) well sclerotized, medium brown. Hypandrium slightly higher than long in lateral view. Processus terminalis narrow even at its base, and tapering evenly until its acute caudal ending, without any trace of median incision. A well sclerotized structure is connected to the dorsal surface of hypandrium. This structure consists of a prominent, sharp crest and a widened anterior part, with two small lateral lobes. Processus lateralis directed caudally, prominent, with moderately long setae. Anterior apodeme of hypandrium ventrally straight, with interrupted median part, laterally wide,
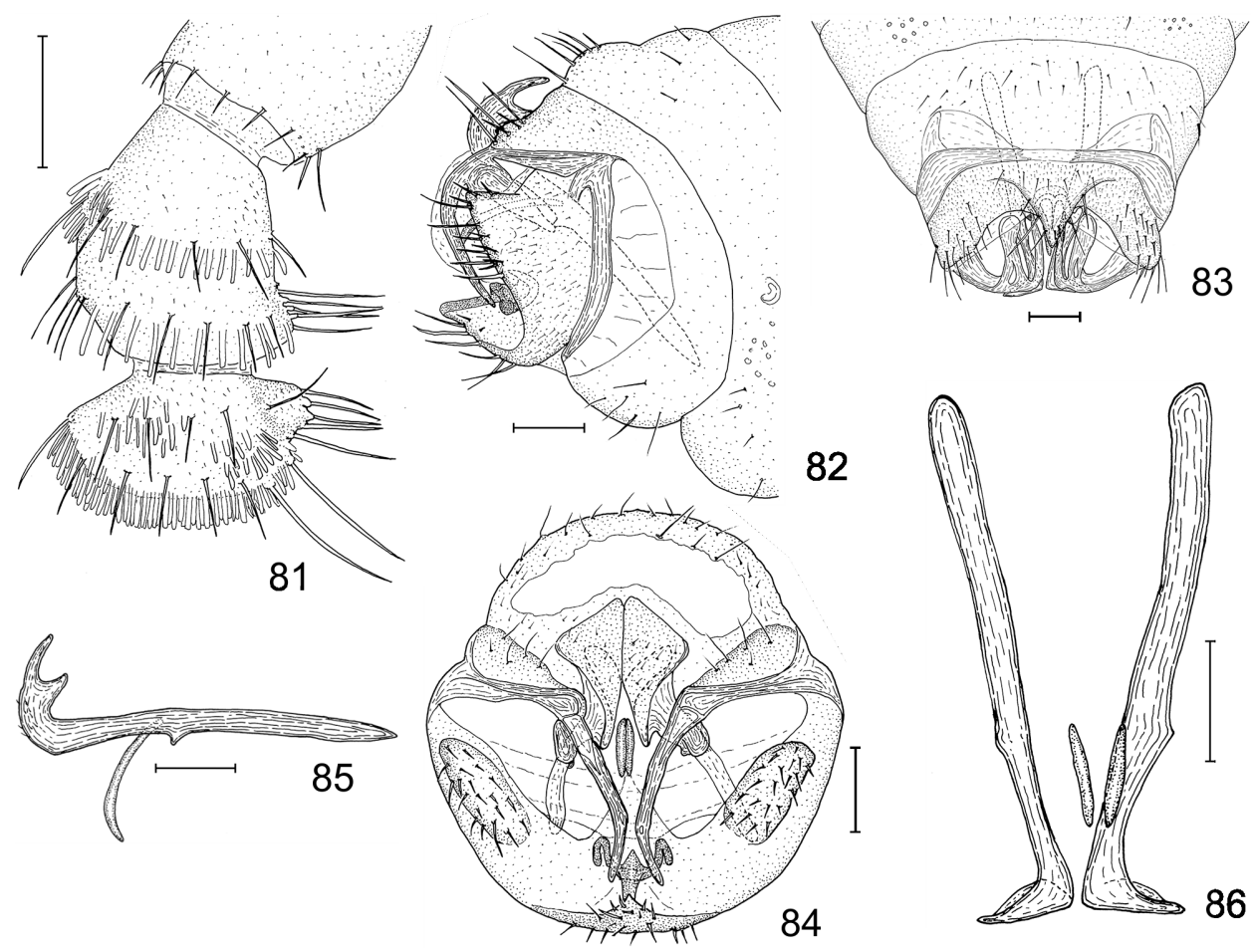

Figs 81-86. Coniopteryx (C.) spinicauda sp. n.: 81 = basal part of antenna, $82=$ male terminalia, lateral view, $83=$ male terminalia, ventral view, $84=$ male terminalia, caudal view, $85=$ paramere and penis, lateral view, $86=$ paramere and penis, ventral view. Scales: $0.04 \mathrm{~mm}$ 
with a hook. Ventral apodeme of gonarcus widened in its anterior third. Stylus forked; its slender and very long outer branch bent forwards, while the inner branch broad, with a hole near to the fork. No distinct ventral bridge between the two inner branches. Paramere long; its anterior part straight, with sharp ending in lateral view. Processus ventralis thin, but recognizable. Processus apicalis with an ending curved upwards and with a distinct subapical lobe. The caudal ending of processus apicalis pointed in lateral view, while gradually widened until its upper third in caudal view. Penis sclerite consists of two long, slender, pointed and curved rods. Between the two processes laterales there is a membraneous structure.

Remarks: Coniopteryx (C.) spinicauda sp. $\mathrm{n}$. belongs to the Coniopteryx lobifrons group sensu SziRÁкI (2005), and because of the narrow and caudally tapering processus terminalis, the similar structure of processus lateralis and stylus it is close to Coniopteryx (C.) angusticauda Sziráki, 2015.

The main distinctive features of the new species are:

- acute processus terminalis of hypandrium, without median incision;

- different sclerotized structure connected to the dorsal surface of hypandrium;

- distinct subapical lobe of processus apicalis of paramere;

- $\quad$ the shape of processus apicalis, which is the most wide at its dorsal third in caudal view;

- the long rods of penis sclerite;

- $\quad$ absence of an additional sclerite above the penis.

Etymology: The new species named after the shape of the acute processus terminalis of the hypandrium.

\section{Coniopteryx (Coniopteryx) toamasinana sp. $\mathrm{n}$.} (Figs 87-92)

Examined material - Holotype: male, Madagascar, Toamasina Province, botanic garden near to entrance to Andasibe National Park, $18^{\circ} 55^{\prime} 35^{\prime \prime}$ S, $48^{\circ} 24^{\prime} 28^{\prime \prime}$ E, $1025 \mathrm{~m}$ a.s.l. 2-8. X. 2001, tropical forest, Malaise trap, leg.: HH; deposited in the collection of CAS; CASTYPE number: 20025. Paratype: 1 male, Madagascar, Antsiranana Province, Sakalava Beach, $12^{\circ} 15^{\prime} 46^{\prime \prime}$ S, $49^{\circ} 23^{\prime} 51^{\prime \prime}$ E, $10 \mathrm{~m}$ a.s.l., 13-16. V. 2001, dwarf littoral forest, Malaise trap, leg.: HH; deposited in HNHM.

Description: Length of the body 1.4-1.7 mm. Head capsule light brown or pale ochreous. Anterior edge of vertex with a laterally flattened projection between the antennae. Eyes large, black. Antennae (Fig. 87) very light brown, 1.2-1.3 mm, 29 segmented. Scape about as wide as long, pedicel 1.2-1.3 times longer than wide. The flagellar segments in the basal half of antennae 2.3-2.4 times, in the apical half 2.0-2.4 times wider than long. Pedicel without any protuberance, while the first flagellar segment has a rather stout inner outgrowth, with short but strong setae. The usual inner seta of this segment is very close to the outgrowth. The usual inner setae of the 2-6 flagellar segments have outstanding bases. 
Ordinary hairs situated mostly in an apical ring on the scape, apically in a ring, otherwise irregularly on pedicel, and rather irregularly on flagellar segments. Scale-like hairs are thinly scattered on large part of pedicel, and arranged in a moderately broad apical whorl on the flagellomeres. Palpi pale ochreous.

Thorax light yellowish-brown, thoracal apodemes and sutures dark brown, shoulder spots medium brown. Legs pale ochreous, wing membrane hyaline, veins clourless. Length of the fore wing $1.8-1.9 \mathrm{~mm}$, of hind wing $1.3 \mathrm{~mm}$. Pregenital part of abdomen pale ochreous.

Male terminalia (Figs 88-92) well sclerotized, medium brown. Hypandrium in lateral view 1.3 times higher than long. Processus terminalis well developed, with acute caudal endings and with u-shaped, broad but moderately deep median incision. An inner hyaline structure - consisting of two rather low longitudinal keels and an anterior transversal part - is connected to the dorsal surface of processus terminalis. (The characteristic pattern of this structure is visible in ventral view by transmitted light.) Processus lateralis moderately long blunt subtriangular and directed caudally. Bases of its relatively short setae rather prominent. Anterior apodeme of hypandrium ventrally straight and rather narrow, laterally widened, without dorsal hook. Ventral apodeme of gonarcus narrow. Stylus forked; its inner branch rather narrow, simple. No detectable ventral bridge between the two inner branches. Pointed outer branch of the stylus bent forwards. Distal part of paramere broad in lateral view. Processus apicalis in lateral view pick-like, in caudal view its main part
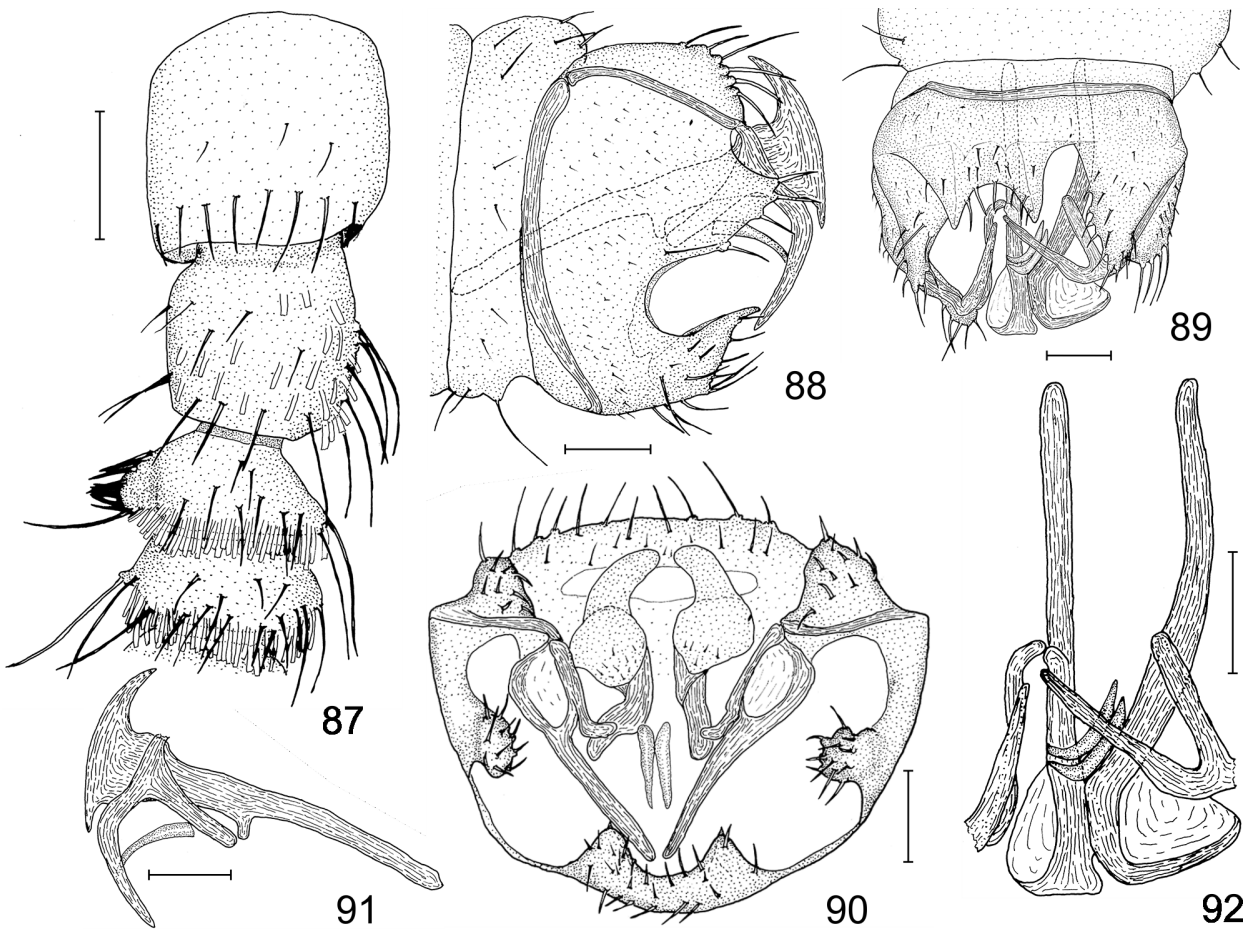

Figs 87-92. Coniopteryx (C.) toamasinana sp. n.: 87 = basal part of antenna, $88=$ male terminalia, lateral view, $89=$ male terminalia, ventral view, $90=$ male terminalia, caudal view , $91=$ male internal genitalia, lateral view, $92=$ male internal genitalia, ventral view. Scales: $0.04 \mathrm{~mm}$ 
bulky, while the dorsal projection curved inwards. Processus ventralis of paramere prominent. Penis sclerite consists of two thin, bent blades.

Remarks: Coniopteryx (C.) toamasinana sp. n. belongs to the Coniopteryx lobifrons group sensu SzIRÁKI (2005). Because of some similarity regarding the building up of processus terminalis - including construction of the dorsal inner structure -, the broad distal part of paramere, the well developed processus ventralis of this sclerite, the narrow ventral apodeme of gonarcus and the absence of a ventral bridge between the inner branches of the stylus Coniopteryx angusticauda Sziráki, 2015 should be regarded as its closest relative.

The main distinctive features of the new species are:

- $\quad$ absence of a group of setae on the pedicel;

- the stout inner outgrowth of the first flagellar segment;

- $\quad$ the broad processus terminalis, with well developed median incision;

- absence of a dorsal hook on the lateral part of the anterior apodeme of hypandrium;

- $\quad$ the dorsal inner structure of hypandrium does not form a reversed bellshape in caudal view;

- in lateral view pick-like processus apicalis of paramere;

- absence of an additional sclerite dorso-caudally of penis.

Etymology: The new species is named after the Toamasina Province, where the holotype of the species was collected.

\section{Coniopteryx (Xeroconiopteryx) antankarana sp. $\mathrm{n}$.} (Figs 93, 95-100)

Examined material - Holotype: male, Madagascar, Antsiranana Province, Montagne d'Ambre National Park, 12³0'52" S, 49¹0'53" E, 960 m a.s.l., 4-19. III. 2001, Malaise trap, leg.: I, ES \& HH; deposited in the collection of CAS; CASTYPE number: 20026. Paratypes: 1 male, Madagascar, Antsiranana Province, $7 \mathrm{~km} \mathrm{~N}$ of Joffreville, $12^{\circ} 20^{\prime} \mathrm{S}, 49^{\circ} 15^{\prime} \mathrm{E}, 360 \mathrm{~m}$ a.s.1., 16-31. V. 2001, dry forest, Malaise trap, leg.: HH; 1 male, Madagascar, Mahajanga Province, Mahavavy River, $6.2 \mathrm{~km}$ SE of Mitsinjo, $16^{\circ} 03^{\prime} 06^{\prime \prime} \mathrm{S}, 45^{\circ} 54^{\prime} 30^{\prime \prime} \mathrm{E}, 20 \mathrm{~m}$ a.s.l., 1-5. XII. 2002, gallery forest, yellow pan trap, leg.: F, G et al.; 1 male, Madagascar, Toliara Province, Zambitse National Park, $22^{\circ} 50^{\prime} 25^{\prime \prime}$ S, 44 $43^{\prime} 52^{\prime \prime}$ E, 825 m a.s.l., 5-12. I. 2002, deciduous spiny forest, Malaise trap, leg.: HH. Two of the paratypes are deposited in the collection of CAS, while one housed in HNHM.

Description: Length of the body 1.4-1.8 mm. Head capsule and palpi light brown. There is a minute, one-segmented, directing slightly upwards, oviform frontal projection between the antennae, with about a dozen setae (Fig. 93). Eyes large, black. Antennae light brown, 0.8-1.0 mm, 25-27 segmented. Scape about as long as wide, or slightly longer, pedicel as wide as long, or slightly wider. Flagellar segments in the basal half of antenna 1.6-2.0 times, in the apical half 1.2-1.8 times wider than long. Ordinary hairs of flagellomeres situ- 
ated rather irregularly (Fig. 95). Scale-like hairs arranged in a dense apical ring on pedicel and on flagellomeres. Inner setae of flagellomeres moderately long.

Thorax pale ochreous, thoracal apodemes and sutures may be light, or dark brown, or partly even black. Legs and shoulder spots medium brown. Wing membrane fuscous or light brown. Length of the fore wing 1.4-1.8, of hind wing 1.2-1.4 mm. Pregenital part of abdomen pale ochreous. The number of wax glands seems to be rather low.

Most part of male terminalia (Figs 96-100) well sclerotized, medium brown. Hypandrium in lateral view more than 2 times higher than long. Processus terminalis is a small but distinct, pointed triangle, without median incision. Processus lateralis short and blunt; bases of its setae rather prominent. Anterior apodeme of hypandrium narrow, medially interrupted or very weak. Gonarcus short and only moderately sclerotized. Ectoproct with moderately long setae on prominent bases. Stylus slightly forked; its inner branch moderately wide in lateral view, and there is a distinct ventral bridge between the two inner branches. Outer branch rudimentary, starting from a lobe of inner branch, and bent up-
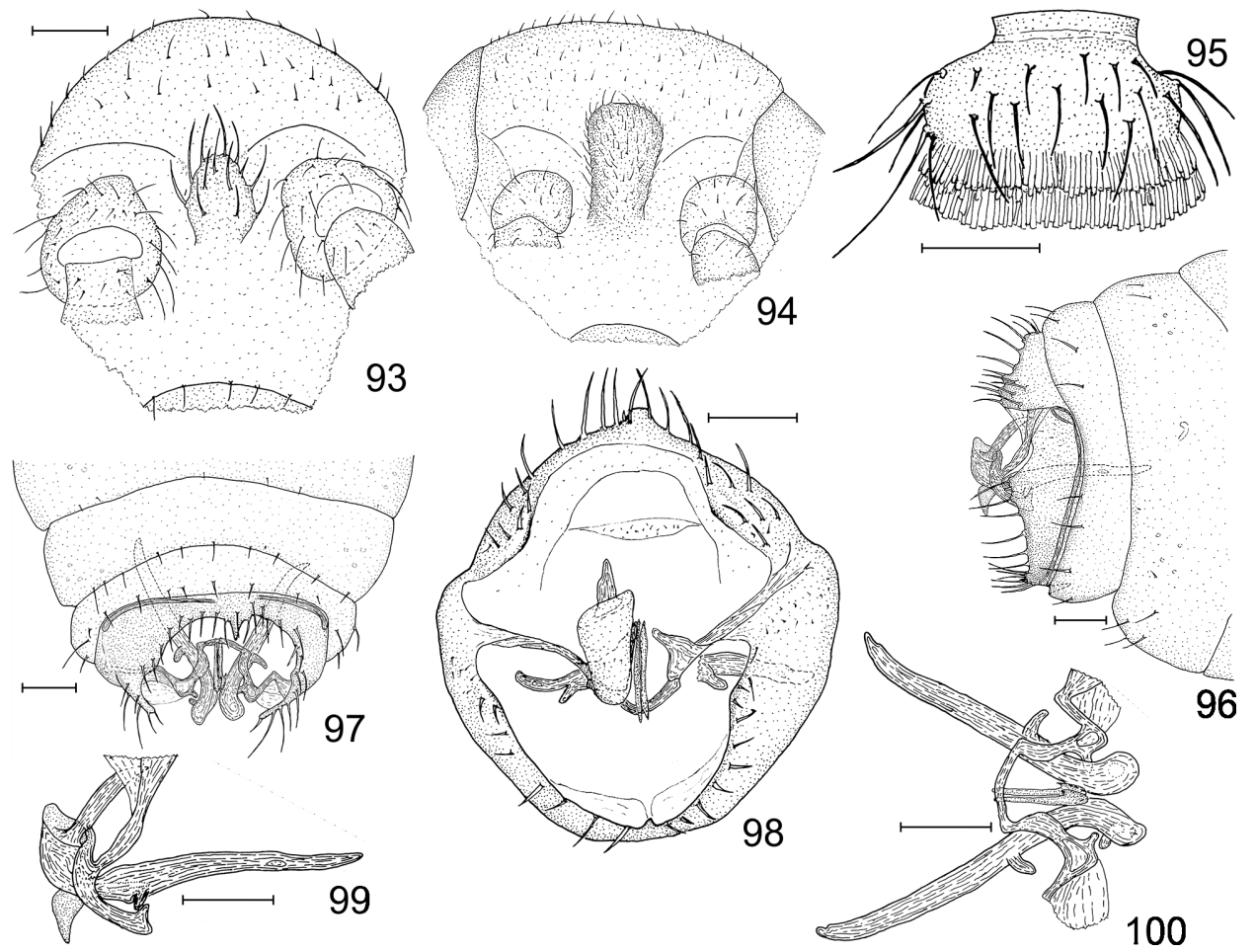

Figs 93-100. 93, 95-100: Coniopteryx (X.) antankarana sp. n.; 93 = frons with frontal projection, 95 = flagellar segment from basal half of antenna, $96=$ male terminalia, lateral view, 97 = male terminalia, ventral view, 98 = male terminalia without distal part of right paramere, caudal view, 99 = male internal genitalia, lateral view, $100=$ male internal genitalia, ventral view. 94: Coniopteryx (X.) sestertia Meinander; frons with frontal projection of male paratype - on the basis of photograph made by Rachel Diaz-Bastin, CAS. Scales: $0.04 \mathrm{~mm}$, but in Fig. 93 it is $0.03 \mathrm{~mm}$ 
wards and inwards. Base of the stylus continued backwards and inwards in a more or less membraneous structure. Distal part of paramere rather broad in lateral view. Processus apicalis consists of an - in lateral view - cup like part and of a long thorn, directed upwards and forwards about in an angle $45^{\circ}$. Processus ventralis distinct, digitiform and directed somewhat laterally. Penis sclerite consists of two slightly hooked blades, broadened at their distal third.

Remarks: Coniopteryx (X.) antankarana sp. n. belongs to the Coniopteryx bicuspis group sensu Sziráki (2005). Because of the presence and basic structure of its frontal projection and of the structure of the male terminalia this species is in closer relation with C. (X.) sestertia Meinander, 1998, C. (X.) triantennata Monserrat, 1994 and C. (X.) wowifuna Monserrat, 1994. As the frontal projection of the latter species - similarly to $C$. (X.) antankarana sp. n. - is simple, with some long setae, I consider $C$. (X.) wowifuna as the closest relative of the new species.

It should be noted that $C$. (X.) sestertia was synonymized under $C$. (X.) triantennata by MonsERrat (2006), and I had accepted it in my book (SzIRÁKI 2011). As there is now a further species with frontal projection of somewhat similar structure within the $C$. bicuspis species group, I asked and received photographs of the head of the holotype and male paratype of $C$. (X.) sestertia, and additional information about their frontal projection from CRISTOPHER C. GRINTER and RAChel Diaz-Bastin (CAS). After the examination of the photographs it became entirely sure that the frontal projection of $C$. sestertia clearly is one-segmented (Fig. 94). This organ of C. triantennata is two-segmented (Monserrat 1994), and there are some differences also in male genitalia of the two species (see below). Consequently, C. (X.) sestertia should be regarded as a valid species.

The main distinctive features of the new species are:

- the one segmented, oviform frontal projection, with about 10-12 setae (while in C. triantennata this organ two segmented, in C. sestertia pluglike with short, dense, slightly curved hairs, in C. wowifuna conic with 3-4 long apical setae);

- the irregularly situated ordinary hairs of the flagellar segments;

- the small but distinct, pointed processus terminalis of hypandrium (which sclerite is similar in C. triantennata, but absent or indistinct in $C$. wowifuna and C. sestertia);

- the (slightly) forked stylus;

- the structure of processus apicalis of paramere, which consists of an - in lateral view - broad, cup-like part and of a long thorn (while in C. wowifuna two long thorns appear in lateral view);

- presence of a distinct processus ventralis of the paramere (which scleritepart is similar in C. sestertia (MeInANDer 1998: Fig. 15/D), but - according to the original description (MonserRat 1994) - absent in C. triantennata and C. wowifuna). 
Etymology: The new species is named after the Antankarana ethnic group inhabiting the northern tip of Madagascar, where the holotype and one of the paratypes were collected.

\section{Coniopteryx (Xeroconiopteryx) botswana Meinander, 1998}

$$
\text { (Figs 101-102) }
$$

Examined material - Holotype: male, Botswana, Serowe, $22^{\circ} 15^{\prime} \mathrm{S}, 26^{\circ} 26^{\prime}$ E, leg.: P. Forchammer, deposited in collection of CAS; other material: 1 male, Madagascar, Antsira-

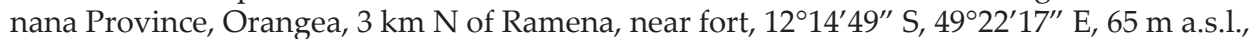
23-27. I. 2001, littoral forest on sand, Malaise trap, leg.: I, ES \& HH; 1 male, Madagascar, Toliara Province, Cap Sainte Marie Special Reserve, $14.9 \mathrm{~km} \mathrm{~W}$ of Morowato, $25^{\circ} 35^{\prime} 40^{\prime \prime}$ S, $45^{\circ} 08^{\prime} 49^{\prime \prime}$ E, $160 \mathrm{~m}$ a.s.l., spiny forest thicket, Malaise trap, leg.: F, G et al.; 1 male, Madagas-

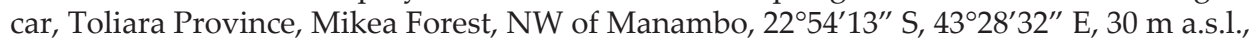
8-19. II. 2002, dry deciduous forest, Malaise trap, leg.: HH; 1 male, same data but 8-18. III. 2002; 1 male, same data but 13-23. VII. 2002; 1 male, same data but 29. VI - 6. VII. 2003; 1 male, same data but 10-21. VIII. 2003.

The examined Madagascan specimens show rather slight or hardly visible variation as compared to the original description, namely: the flagellar segments have two whorls of scale-like hairs (according to the original description only one); the caudal hook of processus apicalis of paramere is simple, while in corresponding figures of the original description (MeINANDER 1998: Figs 14A, D) is bifid; ventral part of anterior apodeme of hypandrium present (according to the original description absent); a short processus terminalis of hypandrium with a shallow median incision present (Fig. 102) (according to the original description absent); the penis formed from two, in lateral view broad blades (according to the original description it consists of two rods); the hypandrium about 2.5 times as high as broad (according to the original description it is 1.5 times higher than broad).

On the other hand, the structure of the paramere, stylus and gonarcus agreed entirely with the original description of C. botswana. Therefore, examination of the holotype of this species seemed necessary. This examination showed that the anterior apodeme of hypandrium of the - probably newly
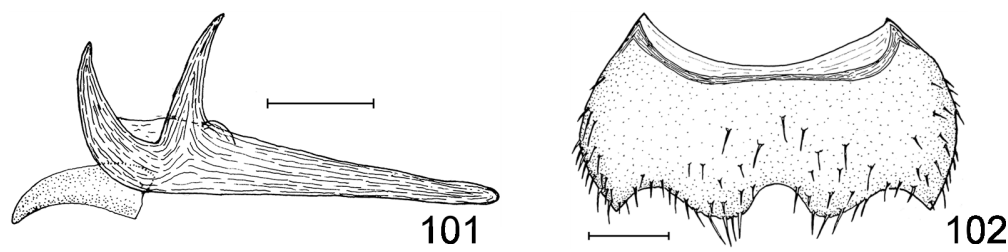

Figs 101-102. Coniopteryx (X.) botswana Meinander, Madagascan specimen: $101=$ paramere and penis, lateral view, 102 = hypandrium, ventral view. Scales: $0.04 \mathrm{~mm}$ 
hatched - holotype specimen present but very weak, the penis in lateral view wide, the caudal hook of processus apicalis of paramere simple (Fig. 101), and the flagellar segments have two whorls of scale-like hairs (however, the second one weakly visible). As the caudal part of hypandrium regards, it was damaged and pushed upwards and forwards, thus the real structure visible only from caudal view. The only remaining alteration between the holotype and the Madagascan specimens is the different height-width relation of hypandrium. However, this feature might be rather variable within the same species (SzIrÁKı 1979: Figs 5-7). Consequently, the given Madagascan specimens are conspecific with the holotype of Coniopteryx (X.) botswana.

\section{Coniopteryx (Xeroconiopteryx) tuleariensis sp. n.}

$$
\text { (Figs 103-108) }
$$

Examined material - Holotype: male, Madagascar, Toliara Province, Berenty Special

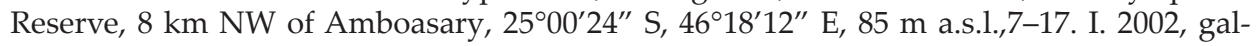
lery forest, Malaise trap, leg.: I, FP \& HH; deposited in the collection of CAS; CASTYPE number: 20027. Paratypes: 1 male, Madagascar, Antsiranana Province, Montagne d'Ambre National Park, $12^{\circ} 30^{\prime} 52^{\prime \prime}$ S, 49¹0'53" E, 960 m a.s.l., 26-29. I. 2001, Malaise trap, leg.: I, ES \& HH; 1 male, Madagascar, Antsiranana Province, Montagne des Français, $7.2 \mathrm{~km} \mathrm{SE}$ of Antsiranana, $12^{\circ} 19^{\prime} 22^{\prime \prime}$ S, $49^{\circ} 20^{\prime} 17^{\prime \prime}$ E, $180 \mathrm{~m}$ a.s.l., 22-28. II. 2001, tropical dry forest, Malaise trap, leg.: F, G, et al.; 1 male, Madagascar, Antsiranana Province, Sakalava Beach, $12^{\circ} 15^{\prime} 46^{\prime \prime}$ S, 49 $9^{\circ} 3^{\prime} 51^{\prime \prime}$ E, $10 \mathrm{~m}$ a.s.l.,16-31. V. 2001, dwarf littoral forest, Malaise trap, leg.: $\mathrm{HH}$; 1 male, Madagascar, Mahajanga Province, Ampijoroa National Park, $160 \mathrm{~km}$ N of Maevatana on RN $04,16^{\circ} 19^{\prime} 10^{\prime \prime}$ S, $46^{\circ} 48^{\prime} 48^{\prime \prime}$ E, 43 m a.s.l., 17-24. VIII. 2003, deciduous forest, Malaise trap, leg.: HH; 1 male, same data but 24-31. VIII. 2003; 2 males, same data but 7-14. IX. 2003; 1 male, same data but 28. IX - 5. X. 2003; 1 male, same data but 2-20. XI. 2003; 1 male, Madagascar, Mahajanga Province, Tsingy de Bemaraha National Park, 3.4 km E of Bekapaka, $19^{\circ} 08^{\prime} 31^{\prime \prime}$ S, $44^{\circ} 49^{\prime} 41^{\prime \prime}$ E, $50 \mathrm{~m}$ a.s.l., 6-10. XI. 2001, tropical dry forest, Malaise trap, leg.: F, G, et al.; 1 male, Madagascar, Toliara Province, Andohahela National Park, Forêt d'Ambohibory, 1.7 km ENE of Tsimelahy, $24^{\circ} 55^{\prime} 48^{\prime \prime}$ S, $46^{\circ} 38^{\prime} 44^{\prime \prime}$ E, $300 \mathrm{~m}$ a.s.l., 16-20. I. 2002, tropical dry forest, leg.: F, G. et al.; 1 male, Madagascar, Toliara Province, Andohahela National Park, Ihazofotsy, Parcelle III, $24^{\circ} 50^{\prime} 05^{\prime \prime}$ S, $46^{\circ} 29^{\prime} 21^{\prime \prime}$ E, $80 \mathrm{~m}$ a.s.l., 28. IV - 6. V. 2003, dry spiny forest, Malaise trap, leg.: I, FP \& HH; 2 males, same data but 20. V -3. VI. 2003; 2 males, same data but 21-29. VI. 2003; 1 male, same data but 13-24. VII. 2003; 3 males, same data but 24. VII - 3. VIII. 2003; 1 male, Madagascar, Toliara Province, An-

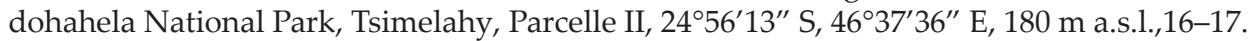
XII. 2002, transitional forest, Malaise trap, leg.: I, FP \& HH; 1 male, same data but 22-29. VI. 2003; 2 males, same data but 10-21. IX. 2003; 2 males, same data but 21. IX - 10. X. 2003; 1 male, same data but 11-19. X. 2003; 2 males, Madagascar, Toliara Province, Berenty Special

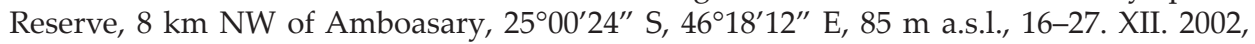
gallery forest, Malaise trap, leg.: I, FP \& HH; 1 male, same data but 5-15. II. 2003; 1 male, same data but 7-17. III. 2003; 1 male, same data but 6-20. VI. 2004; 1 male, Madagascar, Toliara Province, Beza Mahafaly Reserve, Parcelle I, near to research station, $23^{\circ} 44^{\prime} 19^{\prime \prime}$ S, $44^{\circ} 35^{\prime} 28^{\prime \prime}$ E, $165 \mathrm{~m}$ a.s.l., 18-28. VII. 2002, dry deciduous forest, Malaise trap, leg.: HH; 1 male, Madagascar, Toliara Province, Cap Sainte Marie Special Reserve, 14.9 km W of Morovato, $25^{\circ} 35^{\prime} 40^{\prime \prime}$ S, $45^{\circ} 08^{\prime} 49^{\prime \prime}$ E, $160 \mathrm{~m}$ a.s.l., 13-19. II. 2002, spiny forest thicket, Malaise 
trap, leg.: F, G et al.; 1 male, Madagascar, Toliara Province, Cap Sainte Marie Special Re-

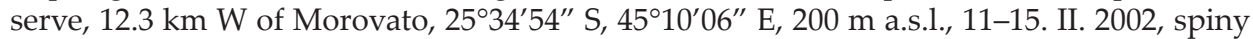
forest thicket, Malaise trap, leg.: F, G et al.; 1 male, Madagascar, Toliara Province, Mikea Forest, NW of Manambo, 22 $54^{\prime} 48^{\prime \prime}$ S, $43^{\circ} 28^{\prime} 56^{\prime \prime}$ E, $37 \mathrm{~m}$ a.s.1., 16-20. XII. 2001, spiny forest, Malaise trap, leg.: HH; 1 male, same data but 8-18. IV. 2002; 3 males, Madagascar, Toliara Province, Tsimanampetsotsa National Park, Forêt de Bemanateza, $23 \mathrm{~km}$ E of Beheloka, 2359'32" S, 4352'50" E, 90 m a.s.l., 22-26. III. 2002, spiny forest thicket, Malaise trap, leg.: F, G et al.; 1 male, Madagascar, Toliara Province, Zambitse National Park, 22 $50^{\prime} 25^{\prime \prime}$ S,

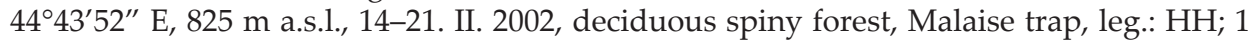
male, same data but 1-14. VIII. 2002; 1 male, Madagascar, Toliara Province, Zambitse Na-

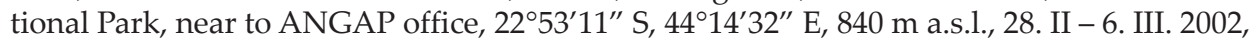
deciduous spiny forest, Malaise trap, leg.: HH. Most of the paratypes are deposited in the collection of CAS, while four housed in HNHM.

Description: Length of the body $1.3-1.9 \mathrm{~mm}$. Head capsule light or medium brown, but genae may be dark brown. Eyes large, black. Antennae light or medium brown, 1.1-1.3 $\mathrm{mm}, 28-31$ segmented. Length-width relation of the antennal segments rather variable; scape usually slightly wider than long, but in some cases slightly (up to 1.2 times) longer than wide. Pedicel 1.1-1.5 times longer than wide. Flagellar segments in the basal half of antennae 1.4-2 times wider than long, while in the apical half about as wide as long, or only slightly wider. Ordinary hairs of the flagellar segments situated in two rather irregular rings. Setae moderately long. Scale-like hairs are scattered on large part of pedicel, and

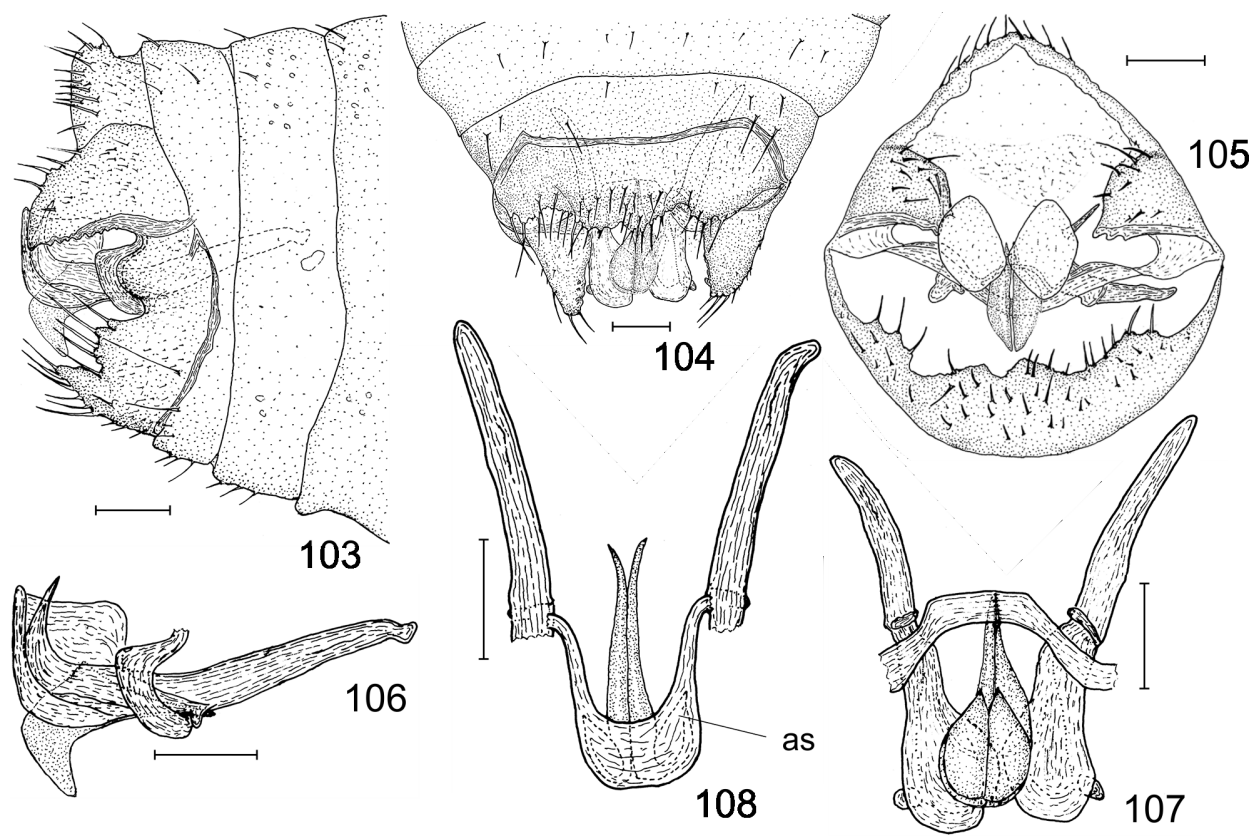

Figs 103-108. Coniopteryx (X.) tuleariensis sp. n.: $103=$ male terminalia, lateral view, $104=$ male terminalia, ventral view, $105=$ male terminalia, caudal view , $106=$ male internal genitalia, lateral view, $107=$ male internal genitalia, ventral view , $108=$ additional sclerite, penis and proximal part of parameres, dorsal view. Abbreviation: as = additional sclerite. Scales: $0.04 \mathrm{~mm}$ 
arranged in a dense, dark or medium brown apical whorl on the pedicel and also on the majority of flagellomeres, with exception of the acron. Besides, scale-like hairs are scattered also on the other parts of pedicel, and the thickness of the above mentioned apical whorls is lessening towards the apex of the flagellum. Palpi light brown.

Thorax pale ochreous, thoracal apodemes and sutures medium or light brown, shoulder spots dark or medium brown. Wing membrane and veins light brown. Length of the fore wing 1.5-1-8 $\mathrm{mm}$, of hind wing 1.2-1.5 $\mathrm{mm}$.

Male terminalia (Figs 103-108) well sclerotized, dark brown. Hypandrium in lateral view 1.5 times higher than long. Processus terminalis in lateral view prominent. Median incision of this sclerite indistinct. Processus lateralis rounded subtriangular, distinct but moderately large. Anterior apodeme of hypandrium narrow but continuous. Its lateral part somewhat undulated, with a thin dorsal hook. Gonarcus rather large, in lateral view bulky. Its ventral apodeme strong, with a more or less finely and bluntly jagged ventral line and with a short or moderately long apical tooth. Stylus unforked, broad and forming a well sclerotized bridge below the parameres. Paramere strong, its proximal part in lateral view especially broad. Processus apicalis of this organ consists of a slightly hooked, dorsally directed thorn which is a continuation of an outer keel originated from the middle of the paramere, and a wide inner lobe which is continued caudally in the usual transverse structure. Processus ventralis of paramere small but distinct. Penis is a paired sclerite, with a dibber-like, in lateral view broad and hooked distal, and a tapering, pointed proximal part. Above the penis there is a thin additional sclerite, originated near to the middle part of parameres, and visible in dorsal or in caudal view.

Remarks: Coniopteryx (X.) tuleariensis sp. n. belongs to the Coniopteryx bicuspis group sensu SzIrÁKi (2005). Because of the similar structure of paramere, the flagellar segments of male antennae and the presence of a well sclerotized bridge below the parameres Coniopteryx bicuspis Tjeder, 1957 should be regarded as its closest relative.

The main distinctive features of the new species are:

- $\quad$ the rather large gonarcus, with a caudal tooth;

- $\quad$ in lateral view prominent processus terminalis of hypandrium;

- $\quad$ presence of a distinct processus lateralis;

- $\quad$ the dibber-like, hooked and in lateral view broad distal part of the paired penis.

Etymology: The new species is named after the earlier name of the Toliara Province, where the holotype and large part of paratypes were collected.

\section{DISCUSSION}

The coniopterygid material studied in the present work contained specimens of 19 species, belonging to the genus Coniopteryx. Among them, Coniopteryx (X.) botswana hitherto known only from Botswana. Coniopteryx (C.) bidentata sp. $\mathrm{n}$. is close to Coniopteryx madagascariensis (Coniopteryx notata group) and also has African relatives. The two new species of the subgenus Xeroconi- 
opteryx also related to African species. Therefore, together with the formerly described C. madagascariensis, five species have African affinity. On the other hand, 14 new species, as the three species described before by the present author from Madagascar (SzIRÁKI 2015), belong to the Coniopteryx lobifrons group, which originally seemed to be a SE Asian species group. According to our present knowledge, this group consists of five species from SE Asia (Singapore, South China, Thailand) and 17 from Madagascar. This disjunct biogeographical distributional pattern is interesting, although not unique.

Within the order Neuroptera the position of two chrysopid species (Plesiochrysa litorosa (Navás, 1911) and P. scotti (Esben-Petersen, 1927), both endemic to Seychelles) is somewhat similar. These species belong to the Plesiochrysa oceanica group, distributed otherwise from the Pacific Islands and Australia to Southern India (Онм \& HöLzel 2002). A more similar pattern is that of the osmylid genus Thyridosmylus, where 17 species are known from SE Asia (including East India) and four from Madagascar ( $\mathrm{X}_{\mathrm{U}}$ et al. 2017).

Some botanical examples may be found as well. There are several plant species, as Amaracarpus pubescens Blume, which live in the Indomalayan Region and in Seychelles (Friedman 1994).

Two explanations seem to be possible for this interesting distribution pattern: the eventual drifting with sea currents on floating groups of timbers and other plant materials, or dispersal on a terrestrial route. The latter route was possible in Late Cretaceous (ca. 80 million years (Ma) ago) when Madagascar (which separated from the African continent well before: ca. $160 \mathrm{Ma}$ ) was in connection with the Indian plate by the Seychelles Plateau, and simultaneously there was a suspectable bridge between India and the later SE Asia (RAGE 2003). Later on, the Indian Plate firmly connected to Eurasia at the Early Eocene (ca. $50 \mathrm{Ma}$ ). WANG et al. (2011), based on of a phylogenetic analysis of the genus Thyridosmylus, render it probable that this group of insects, developed originally in Madagascar, got over to Eurasia at this time. Regarding its large diversity in Madagascar, this terrestrial dispersal route seems to be probable also in the case of the Coniopteryx lobifrons species group. Probability of the terrestrial dispersal of dusty lacewings between South Asia and Madagascar appears to be strengthened by the suspected relations of Coniopteryx (C.) ihorombeana sp. n. and Coniopteryx (C.) pseudoceylonica sp. n. with certain South Asian species of the genus.

Acknowledgements - I am grateful to the late Dr. Norman D. Penny for the possibility to examine the extremely interesting Madagascan coniopterygid material of CAS and for the kind loan of the holotype of Coniopteryx botswana. I am indebted also to Christopher Grinter, collection manager of the Department Entomology (CAS) for the possibility to obtain information about holotype and male paratype of Coniopteryx sestertia, and to Ra- 
chel Diaz-Bastin (CAS) for the photographs and written information about the head of the above-mentioned specimens. I owe Professor Roberto Pantaleoni (Sassari) and two unnamed referees thanks for their helpful proposals and thorough work.

\section{REFERENCES}

Aspöск, U. (2019): Toward a homologization of male genital sclerites in Coniopterygidae (Neuroptera) - A tightrope dance. Pp. 63-78. In: Weinrauch, F., Frank, O., Gruppe, A., Jepson, J., Kirschey, L. \& Ohm, M. (eds): Proceedings of the XIII. International Symposium of Neuropterology, Laufen/Germany, 17-22 June 2018. - Osmylus Scientific Publishers, Wolzach. https://doi.org/10.5281/zenodo.3569381

Fraser, F. C. (1952): New additions to the fauna of Madagascar. - Mémoires de l'Institut Scientifique de Madagascar. Serie E. Entomologie 1: 135-143.

Friedman, F. (1994): Seychelles. Pp. 288-292. In: Davis, S. D., Heywood, V. H. \& Hamilton, A. C. (eds): Centres of plant diversity. Vol. 1. - IUCN Publications Unit, Cambridge.

Meinander, M. (1972): A revision of the family Coniopterygidae (Planipennia). - Acta Zoologica Fennica 136: 1-357.

Meinander, M. (1974): Coniopterygidae from Madagascar (Neuroptera). - Notulae Entomologicae 54: 60-63.

Meinander, M. (1998): Coniopterygidae (Neuroptera) from southern and eastern Africa. African Entomology 6: 117-146.

Monserrat, V. (1994): Nuevos datos sobre los Coniopterygidos de las regiones Palearctica y Afrotropical (Neuroptera: Coniopterygidae). - Graellsia 50: 109-127.

Monserrat, V. (2006): New taxonomic and faunistic data on the dusty wings from Senegal (Insecta, Neuroptera, Coniopterygidae). - Graellsia 62: 13-24. https://doi.org/10.3989/ graellsia.2006.v62.i1.25

Онм, P. \& HöLzel, H. (2002): Zoological patterns in Chrysopidae of the Madagascan subregion (Insecta: Neuroptera). - Acta Zoologica Academiae Scientiarum Hungaricae 48(Suppl. 2): 229-252.

RAGE, J-C. (2003): Relationships of the Malagasy fauna during Late Cretaceous: northern or southern routes?. - Acta Palaeontologica Polonica 48: 661-662.

SzIrÁkI, Gy. (1979): Notes on Hungarian species of Coniopterygidae from different orchards. - Folia entomologica hungarica 32: 181-184.

SzIrÁKI, Gy. (2005): Species grouping of several genera and subgenera of Coniopterygidae (Neuroptera). - Folia entomologica hungarica 66: 101-136.

SzIrákI, Gy. (2011): Coniopterygidae of the world. - LAP Lambert Academic Publishing, Saarbrücken, $249 \mathrm{pp}$.

SZIRÁKI, Gy. (2015): Identity of Coniopteryx madagascariensis Meinander, 1974 (Neuroptera: Coniopterygidae), with description of three new species. - Acta Zoologica Academiae Scientiarum Hungaricae 61: 135-146. https://doi.org/10.17109/AZH.61.2.135.2015

WANG, Y. J., Winterton, S. L. \& Liv, Z. Q. (2011): Phylogeny and biogeography of Thyridosmylus (Neuroptera, Osmylidae). - Systematic Entomology 36: 330-339. https://doi. org/10.1111/j.1365-3113.2010.00565.x

Xu, H., Winterton, S. L., Wang, Y. J. \& Liu Z. Q. (2017): Two new species of Thyridosmylus Krüger, 1913 from Madagascar (Neuroptera, Osmylidae). - Zookeys 724: 43-52. https://doi.org/10.3897/zookeys.724.21057

Received February 6, 2020, accepted May 30, 2020, published August 14, 2020 